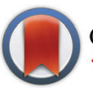

CrossMark

\&lick for updates

Cite this: Nanoscale, 2015, 7, 1250

\section{Graphene-based transition metal oxide nanocomposites for the oxygen reduction reaction}

\author{
Meng Sun, ${ }^{a, c}$ Huijuan Liu, ${ }^{a}$ Yang Liu, Jiuhui $Q u^{\star a}$ and Jinghong Li*b
}

The development of low cost, durable and efficient nanocatalysts to substitute expensive and rare noble metals (e.g. Pt, $\mathrm{Au}$ and $\mathrm{Pd}$ ) in overcoming the sluggish kinetic process of the oxygen reduction reaction (ORR) is essential to satisfy the demand for sustainable energy conversion and storage in the future. Graphene based transition metal oxide nanocomposites have extensively been proven to be a type of promising highly efficient and economic nanocatalyst for optimizing the ORR to solve the world-wide energy crisis. Synthesized nanocomposites exhibit synergetic advantages and avoid the respective disadvantages. In this feature article, we concentrate on the recent leading works of different categories of introduced transition metal oxides on graphene: from the commonly-used classes $\left(\mathrm{FeO}_{x}, \mathrm{MnO}_{x}\right.$, and $\mathrm{CoO}_{x}$ ) to some rare and heat-studied issues $\left(\mathrm{TiO}_{x}, \mathrm{NiCoO}_{x}\right.$ and $\left.\mathrm{Co}-\mathrm{MnO}_{x}\right)$. Moreover, the morphologies of the supported oxides on graphene with various dimensional nanostructures, such as one dimensional nanocrystals, two dimensional nanosheets/nanoplates and some special multidimensional frameworks are further reviewed. The strategies used to synthesize and characterize these well-designed nanocomposites and their superior properties for the ORR compared to the traditional catalysts are carefully summarized. This work aims to highlight the meaning of the multiphase establishment of graphene-based transition metal oxide nanocomposites and its structural-dependent ORR performance and mechanisms.
Received 5th October 2014, Accepted 18th November 2014 DOI: $10.1039 / c 4 n r 05838 \mathrm{k}$ www.rsc.org/nanoscale devices. Therefore, in order to overcome the limitations of ORR performance, the requirements of advanced electrode materials with outstanding features, including resourceful storage, abundant mesoporous variety, strength, long durability, decorative facial chemistry, sustainable and wide potential window and environmental friendliness, are crucial. In electrode materials for ORR, a variety of precious metals, metal oxides and sulfides with specific shapes, ${ }^{1,2}$ bimetallic/ intermetallic compositions, ${ }^{3}$ and core-shell nanostructures ${ }^{4}$ have acquired some achievements in optimizing catalytic activity for ORR. Nevertheless some drawbacks, such as high cost, crossover effects and CO poisoning, ${ }^{5}$ are intractable, and these troubles inevitably lead to electrode pulverization and the loss of the electrocatalytic capacity.

Non-noble nanocatalysts, including transition metal chalcogenides, ${ }^{6}$ nitrides, ${ }^{7,8}$ oxides ${ }^{9}$ and heteroatom-doped carbonaceous (e.g. graphite, carbon nanotubes, graphene and graphene oxides), ${ }^{10}$ have been recently identified for highly catalyzing the ORR. One of the most important categories is transition metal oxides. Transition metal oxides have been intensively studied to be widely used in various fields. In addition to its well-known superiority, the other predominant characteristics of transition metal oxides for their groundbreaking application in the ORR should be highlighted: (1) abundant hydroxyl groups are inserted on the surfaces of transition metal oxides, which could be further functionalized by 
genetic materials (DNA and RNA) for biological catalysts; ${ }^{11}$ (2) crystalline construction of transition metal oxides often have strong interactions, which could prevent the agglomeration of metal particles and maintain small metal particle sizes; ${ }^{12,13}(3)$ they have considerably higher alkaline corrosion resistance in the electrochemical environment compared to noble metal and carbon-based materials due to the stabilization of the high oxidation state of transition metallic elements. In the past decade, due to excellent nanocomposite catalysts, novel advanced material-based transition metal oxides were created. The attractive hierarchically porous structures, ${ }^{14}$ highly conductive networks, ${ }^{15}$ and heterogeneous growth or assembly of transition metal oxides supported on carbonaceous substrates (graphene, meso-/micro-porous carbon and carbon nanotubes $)^{16,17-21}$ have exhibited remarkable electrocatalytic performance in the ORR compared to their unsupported counterparts. ${ }^{22}$

Graphene, which flourished from $2004,{ }^{23}$ is a two-dimensional (2D) single layer carbon allotrope and is arranged in a hexagonal lattice built by $\mathrm{sp}^{2}$-hybridized carbon atoms. ${ }^{24}$ It shows unique merits, for example, a super theoretical specific surface area of $2620 \mathrm{~m}^{2} \mathrm{~g}^{-1} \cdot{ }^{25}$ Moreover, the layer-by-layer graphene structured by $\pi-\pi$ stacking interactions has high thermodynamic stability, and this special layered construction is beneficial for the acceleration of electrons moving between the layers even at ambient temperature. ${ }^{26}$ In particular, more advantages, such as excellent electrical conductivity, high-performance of charge carrier mobility, high levels of transparency accompanied with perfect mechanical strength, make graphene hugely and inestimably potential for the top scientific applications.

Graphene-based materials also outperform graphene in various fields, such as in electronic or photo detectors, ${ }^{27,28}$ capacitors, ${ }^{29,30}$ transparent electrodes, ${ }^{28}$ sensors, ${ }^{31}$ electrocatalysis, ${ }^{32,33}$ environmental remediation,,$^{34-36}$ and energy applications. $^{37}$ The successful achievements of graphene-based devices benefit from their ideal single-atom thick substrates for the growth of functional nanomaterials. Graphene substrates can act as a large electron carrier for highly-efficient electronic exchange between graphene and the decorations, which essentially motivate graphene-based nanocomposites electrochemically. Combining graphene substrates with the corresponding recognition sites of addends may avoid both defects on electrical conductivity and self-construction, and distinctly exhibit their electrocatalytic activity owing to the selective exposure of activated sites. ${ }^{38}$ In addition, the elaborate structured addends, to some extent, play a vital role in the further elevation of electrocatalytic activity of graphene-based nanocomposites. The addends often display different morphologies with multi-dimensional addends, such as one-dimensional (1D) nanorods/nanowires, two-dimensional (2D) nanosheets/nanoplates and three-dimensional (3D) nanoflowers/hollow-nanospheres. Apparently, these special structures contribute to the super charge storage and orderly electron transportation. In particular, the ORR requires high quality graphene-based electrodes with specified surface chemical structures, which is the aim for electrocatalyzing the kinetically sluggish reaction. ${ }^{39}$ Generally, when graphene-based nanocomposites are used as elec- trode materials for the ORR, the following advantages cannot be ignored. (1) The flexibility and immobilization of graphene nanosheets and nanotubes can provide a large space to accommodate and support the addends, and prevent their agglomeration. (2) The good superficial characteristics of graphene increase the solid-air contact efficiency, resulting in a large amount of oxygen adsorption on graphene. (3) The perfect structure of graphene strengthens its electrical conductivity. In particular, the electron transfer rate on the surface of graphene is significantly increased. (4) The structural defects of carbon atoms on single layered graphene provide more active sites for the functionalization of active groups, which stimulates the electrocatalytic ORR.

\section{Graphene-supported transition metal oxides}

\subsection{Iron oxides $\left(\mathrm{FeO}_{x}\right)$}

Due to the abundant storage, low cost, and various crystalline structures of iron oxides, the decorations of $\mathrm{FeO}_{x}$ on graphene supports have been paid more attention. By depositing on graphene, the troubles of dissolution, sintering, and agglomeration of metal oxide catalysts during electrochemical processes can be avoided. The synergetic promotion of chemical coupling effects between graphene sheets and metal oxides has great influence on the electrocatalytic activities of ORR. ${ }^{40-42}$

The synthesis of $3 \mathrm{D} \mathrm{Fe}_{3} \mathrm{O}_{4} / \mathrm{N}$-doped graphene (N-graphene) hybrids through hydrothermal self-assembly, freeze-drying and pyrolysis exhibited excellent electrocatalytic activity for the ORR in alkaline electrolytes ${ }^{43}$ such as a lower onset potential, higher current density, lower $\mathrm{H}_{2} \mathrm{O}_{2}$ generation with electron transfer number $(\sim 4)$, and better durability. Fig. 1a-c show the $3 \mathrm{D}$ macroporous structure and uniform distribution of $3 \mathrm{D}$ $\mathrm{Fe}_{3} \mathrm{O}_{4}$ nanospheres supported on a transparent N-graphene

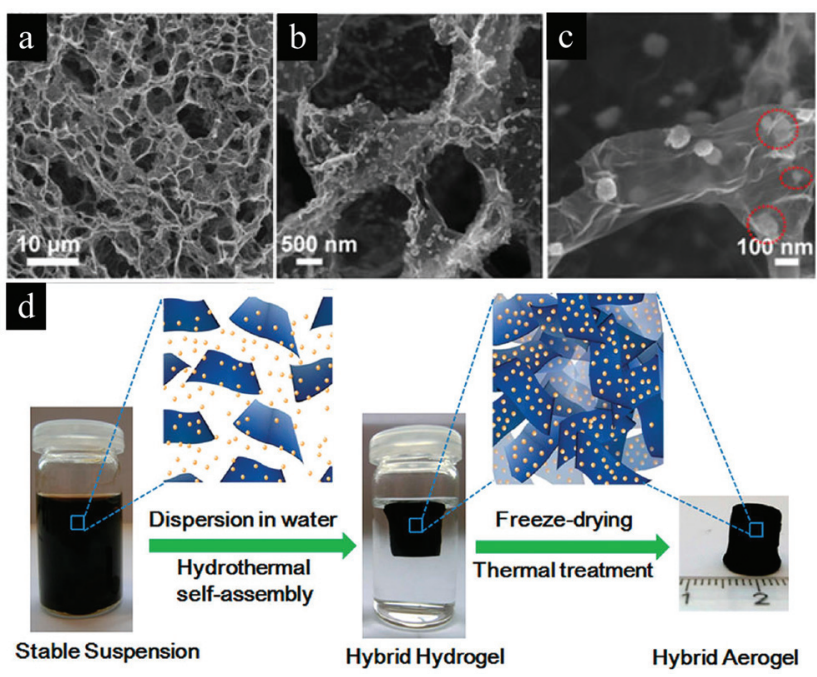

Fig. 1 (a-c) Typical SEM images of 3D $\mathrm{Fe}_{3} \mathrm{O}_{4} / \mathrm{N}$-graphene catalysts. (d) Fabrication processes for the $3 \mathrm{D} \mathrm{Fe}_{3} \mathrm{O}_{4} / \mathrm{N}$-graphene catalysts. Reproduced with permission from ref. 43. Copyright ACS 2013. 
layer. The unique 3D construction of hybrids contributed to an ORR electrocatalytic activity with $-0.26 \mathrm{~V}$ and $1.46 \mathrm{~mA} \mathrm{~cm}{ }^{-2}$, which can be compared to the traditional Pt/C. Specifically, as observed in Fig. 1d, 3D structures are obtained by heat-treated monolithic $\mathrm{Fe}_{3} \mathrm{O}_{4} / \mathrm{N}$-graphene hybrid aerogels.

One category of iron oxides thermally synthesized from iron organic complex precursors (e.g. iron phthalocyanine $\mathrm{e}^{15,40,41}$ and iron tetrasulfophthalocyanine ${ }^{44}$ ) supported on a graphene layer not only prevented the aggregation of graphene nanosheets, but also gave an optimize current density close to that of a $\mathrm{Pt} / \mathrm{C}$ cathode. ${ }^{40}$ Actually, the iron phthalocyanine/graphene (so-called g-FePc composite) was eventually placed into a convection oven set at $160{ }^{\circ} \mathrm{C}$ for $12 \mathrm{~h}$ in a noble gas, which led to the final formation of a mixture of iron oxides (e.g. $\mathrm{Fe}_{2} \mathrm{O}_{3}$ or $\mathrm{Fe}_{3} \mathrm{O}_{4}$ ). As shown in Fig. 2b, the nanoparticles of iron oxides were well-dispersed on both sides of the graphene nanosheet, and the 2D nanosheets can be further constructed through forceful $\pi-\pi$ interactions to a layered 3D structure. ${ }^{45}$ This as-synthesized g-FePc nanocomposites possessed prominent ORR catalytic activity with an excellent cyclic voltammogram (CV) performance of onset potential $-0.18 \mathrm{~V}$ and corresponding current density $3 \mathrm{~mA} \mathrm{~cm}{ }^{-2}$, which is comparable with commercial Pt/C. Moreover, the calculated electron transfer number was found to vary between 3.87 and 3.93, suggesting that the ORR activity of the $2 \mathrm{D}$ nanocatalysts significantly improved by the graphene support compared to FePc alone. $\mathrm{Fe}_{2} \mathrm{O}_{3} / \mathrm{Graphene}$ oxide (GO), ${ }^{46}$ nitrogen-doped reduced graphene oxide ( $\mathrm{N}$-rGO) ${ }^{47}$ and active $\mathrm{Fe}_{2} \mathrm{O}_{3}$ /graphene nano-flakes $(\mathrm{GNF})^{48}$ nanocomposites were proven to be sufficient for electrochemically active ORR. In general, the simultaneous deposition of $\mathrm{Fe}_{2} \mathrm{O}_{3}$ into the $3 \mathrm{D}$ graphene network shows a positive synergistic effect with respect to the electrochemical capacity and durability.

\subsection{Cobalt oxide $\left(\mathrm{CoO}_{x}\right)$}

Cobalt oxides $\left(\mathrm{CoO}_{x}\right) /$ graphene nanostructures have been proven to be a class of active electrocatalysts for ORR and have
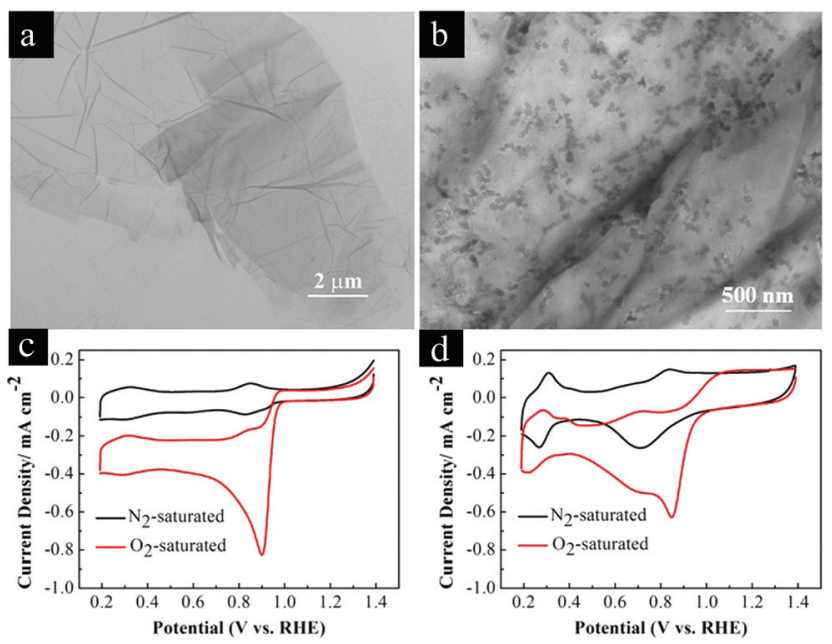

Fig. 2 TEM image of (a) the synthesized graphene nanosheet and (b) $\mathrm{g}-\mathrm{FePc}$ composite. (c) CV curves of ORR on the g-FePc and (d) Pt/C electrodes in $\mathrm{N}_{2}$ - and $\mathrm{O}_{2}$-saturated $0.1 \mathrm{M} \mathrm{KOH}$ at a scan rate of $10 \mathrm{mV}$ $\mathrm{s}^{-1}$. Reproduced with permission from ref. 15. Copyright ACS 2013. aroused wide attention in both the experimental and theoretical science fields. ${ }^{10,49}$ Anchoring nanostructured cobalt oxide particles on flexible and electrically conductive graphene nanosheets yields promising alternative electrocatalysts, which can efficiently take advantages of the combinative merits of cobalt oxides and graphene. ${ }^{50}$ In addition, by nanocomposite synthesis, the facial functionalized hydroxyl, carboxyl and epoxide can interact with metal precursors, which is helpful for the nucleation and formation of oxide nanoparticles. ${ }^{24}$

$\mathrm{Co}_{3} \mathrm{O}_{4}$ supported on graphene nanocomposites with $2 \mathrm{D}$ or $3 \mathrm{D}$ structures exhibited superior ORR electrocatalytic activity in alkaline media. ${ }^{51-53}$ Due to the strong covalent interaction between $\mathrm{N}$ and $\mathrm{Co}$, the $\mathrm{Co}^{3+}$ in $\mathrm{Co}_{3} \mathrm{O}_{4}$ can be partially reduced to $\mathrm{Co}^{2+}$ and it varies spatially on and among individual $\mathrm{Co}_{3} \mathrm{O}_{4}$ nanocrystal/graphene nanosheets. ${ }^{54}$ Therefore, $\mathrm{Co}_{3} \mathrm{O}_{4} / \mathrm{N}$-doped reduced mildly oxidized GO sheets (N-rmGO) nanocomposites were synthesized by a two-step method. ${ }^{55}$ Transmission electron microscopy (TEM) reveals intensive $\mathrm{Co}_{3} \mathrm{O}_{4}$ crystalline spinel structures with size of $\sim 4-8 \mathrm{~nm}$ (Fig. 3a) coordinated with $\mathrm{N}$-rmGO nanosheets displaying a specific 3D structure. $\mathrm{CV}$ curves of $\mathrm{Co}_{3} \mathrm{O}_{4} / \mathrm{N}$-rmGO revealed more efficient activity of ORR in alkaline solutions than $\mathrm{Co}_{3} \mathrm{O}_{4} / \mathrm{rmGO}$ and $\mathrm{Pt} / \mathrm{C}$ (Fig. 3b). As shown in Fig. 3c, the electron transfer number $(n)$ of $\mathrm{Co}_{3} \mathrm{O}_{4} / \mathrm{N}$-rmGO was calculated to be $\sim 3.9$ at $0.60-0.75 \mathrm{~V}$, resulting in the low measured $\mathrm{HO}_{2}{ }^{-}$yields of $\mathrm{Co}_{3} \mathrm{O}_{4} / \mathrm{N}-\mathrm{rmGO}$ $\sim 6 \%$ compared with $\mathrm{Co}_{3} \mathrm{O}_{4} / \mathrm{rmGO} \sim 12 \%$ (Fig. 3d). In addition to an excellent behavior of ORR, the $\mathrm{Co}_{3} \mathrm{O}_{4} / \mathrm{N}$-rmGO was also proven to be highly active for oxygen evolution reaction (OER). Dai's group ${ }^{56}$ further synthesized a series of nanocomposites
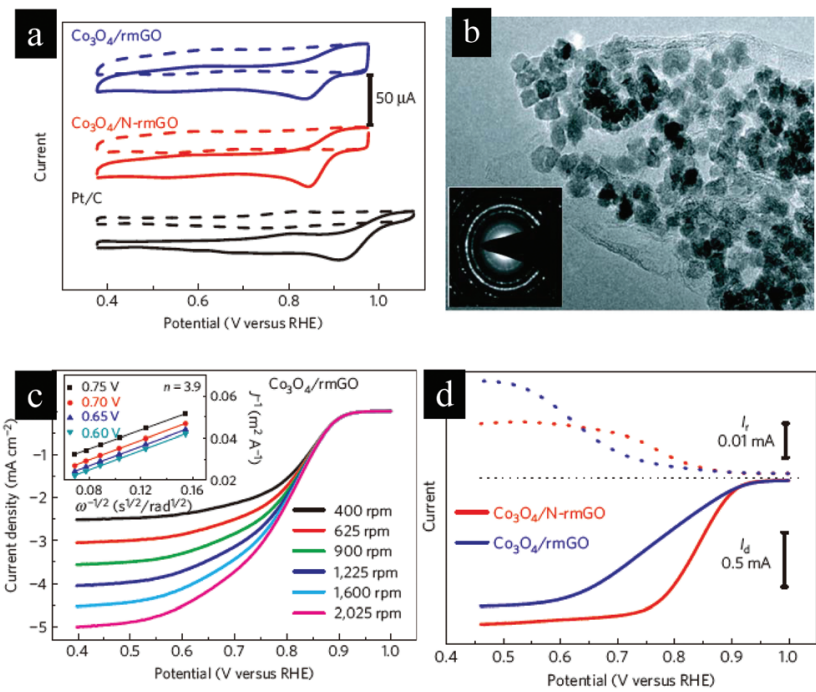

Fig. 3 (a) TEM images of $\mathrm{Co}_{3} \mathrm{O}_{4} / \mathrm{N}$-rmGO. (b) $\mathrm{CV}$ curves of $\mathrm{Co}_{3} \mathrm{O}_{4} /$ rmGO, $\mathrm{Co}_{3} \mathrm{O}_{4} / \mathrm{N}-\mathrm{rmGO}$ and $\mathrm{Pt} / \mathrm{C}$ on glassy carbon electrodes in $\mathrm{O}_{2^{-}}$ saturated (solid line) or Ar-saturated $0.1 \mathrm{M} \mathrm{KOH}$ (dash line). Catalyst loading was $0.17 \mathrm{mg} \mathrm{cm}^{-2}$ for all samples. (c) Rotating-disk voltammograms of $\mathrm{Co}_{3} \mathrm{O}_{4} / \mathrm{N}$-rmGO. (d) Rotating ring-disk electrode voltammograms of $\mathrm{CO}_{3} \mathrm{O}_{4} / \mathrm{rmGO}$ and $\mathrm{CO}_{3} \mathrm{O}_{4} / \mathrm{N}$-rmGO in $\mathrm{O}_{2}$-saturated $0.1 \mathrm{M} \mathrm{KOH}$ at $1600 \mathrm{rpm}$. The disk potential was scanned at $5 \mathrm{mV} \mathrm{s}^{-1}$ and the ring potential was constant at $1.5 \mathrm{~V}$ versus RHE. Reproduced with permission from ref. 54. Copyright Nature 2011. 


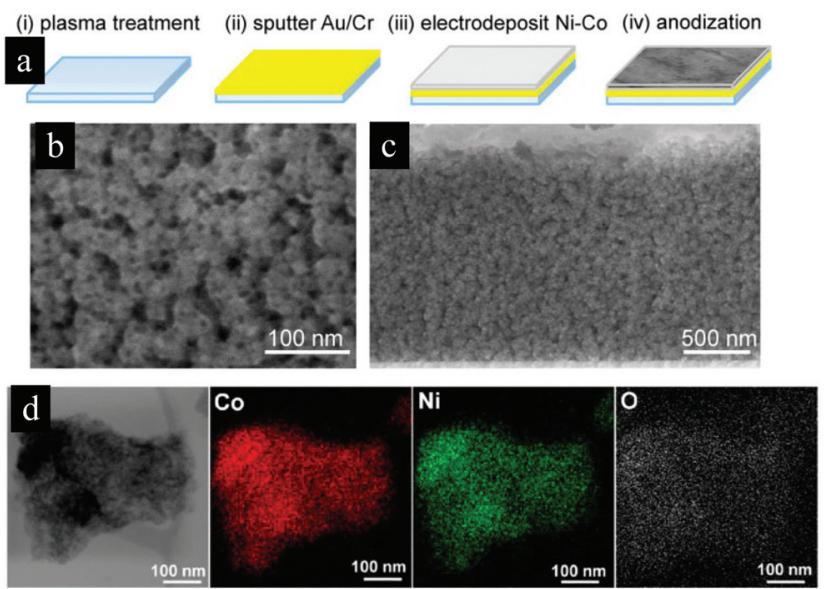

Fig. 4 Fabrication process and electron micrographs of the $\mathrm{Ni}-\mathrm{Co}$ binary oxide NPL: (a) schematic illustration outlining NPL fabrication; (b) and (c) surface and cross-sectional images of NPL (10 atom\% Co); (d) TEM image of NPL and corresponding elemental maps of $\mathrm{Co}, \mathrm{Ni}$, and O. Reproduced with permission from ref. 57. Copyright ACS 2014.

consisting of $\mathrm{MnCo}_{2} \mathrm{O}_{4}$ nanocrystals grown on graphene nanosheets (GNs) as excellent ORR electrocatalysts, which boomed interest about cobalt oxide based bi-metal-oxides supported on graphene nanocomposites. An amorphous Co-Ni binary oxide nanoporous layer (NPL) is schematically electrodeposited using $\mathrm{NiSO}_{4}$ and $\mathrm{CoSO}_{4}$ (Fig. 4). The produced Co$\mathrm{MnO}_{x} / \mathrm{GNs}, \mathrm{Co}-\mathrm{NiO}_{x} / \mathrm{GNs}^{57}$ and $\mathrm{Co}-\mathrm{FeO}_{x} / \mathrm{GNs}^{58}$ nanocomposites also showed high electrocatalytic activity, stability and long durability in alkaline media, which surely qualified as advanced electrocatalysts with for energy conversion and storage.

Another kind of cobalt oxides based graphene catalyst was reported ${ }^{59}$ in which Co nanoparticles assembled on graphene sheets with a layer of $\mathrm{CoO}(\mathrm{Co}-\mathrm{CoO} / \mathrm{GNs})$ were successfully synthesized. As can be seen from Fig. $5 \mathrm{a}$ and b, polyporous $\mathrm{Co} /$ $\mathrm{CoO}$ nanoparticles (NPs) can be pre-synthesized and dispersed on the surface of graphene through self-assembly in solution. The resulting hollow and paramagnetic nanospheres with a diameter of $10 \mathrm{~nm}$ exhibited desirable ORR performance in alkaline conditions such as a better positive half-wave potential $(-0.176 \mathrm{~V})$ than the commercial $\mathrm{Pt} / \mathrm{C}$, and an unexpected nearly $4 \mathrm{e}$ oxygen reduction kinetic process was obtained from its corresponding $\mathrm{K}-\mathrm{L}$ plots at $-0.5 \mathrm{~V}$ (Fig. $5 \mathrm{~d}$ ). Moreover, the stability test of $\mathrm{Co}-\mathrm{CoO} / \mathrm{GNs}$ was carried out by a chronoamperometric method. The results demonstrated that the produced Co-CoO/GNs nanocomposites had good ORR activity and long-term stability as well as commercial $\mathrm{Pt} / \mathrm{C}$ and showed a great potential for promising applications in ORR.

\subsection{Manganese oxide $\left(\mathrm{MnO}_{x}\right)$}

The family of $\mathrm{MnO}_{x}$ has complex members such as $\mathrm{MnO}_{2}$, $\mathrm{Mn}_{2} \mathrm{O}_{3}$, and $\mathrm{Mn}_{3} \mathrm{O}_{4}$. It is reasonable that the diversity of crystallographic structures and morphologies of the $\mathrm{MnO}_{x}$ species contribute to great differences in various catalytic activities, ${ }^{60-64}$ particularly for ORR. Some work have confirmed the ORR activity on different $\mathrm{MnO}_{x}$ materials alone: $\mathrm{Mn}_{5} \mathrm{O}_{8}<$
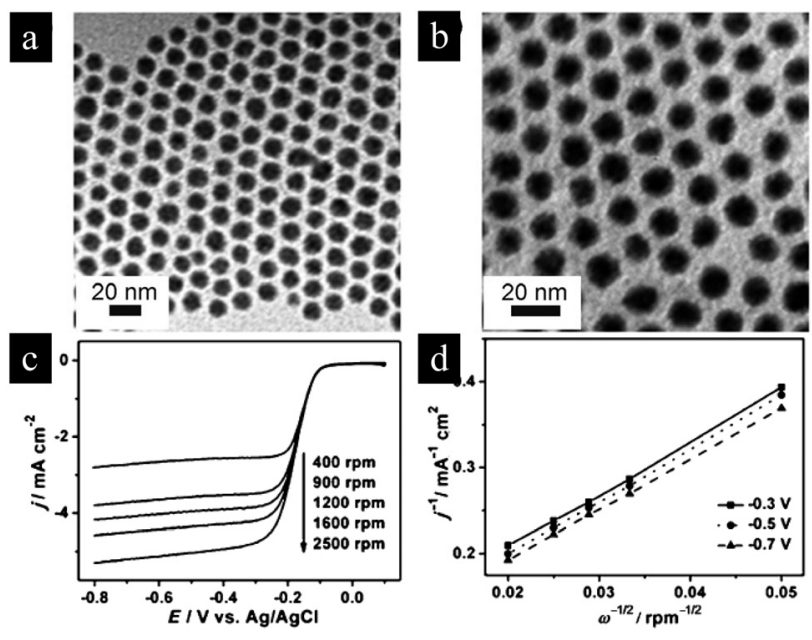

Fig. 5 TEM images of Co NPs (a) and $\mathrm{Co} / \mathrm{CoO}$ core/shell NPs (b). (c) ORR polarization curves of $\mathrm{Co}-\mathrm{CoO} / \mathrm{GNs}$ at different rotation rates. (d) $\mathrm{K}-\mathrm{L}$ plots of the ORR from $\mathrm{Co}-\mathrm{CoO} / \mathrm{GNs}$ in $\mathrm{O}_{2}$-saturated $0.1 \mathrm{M} \mathrm{KOH}$ solution. Reproduced with permission from ref. 59. Copyright Wiley 2012.

$\mathrm{Mn}_{3} \mathrm{O}_{4}<\mathrm{Mn}_{2} \mathrm{O}_{3}<\mathrm{MnOOH} .{ }^{61}$ In fact, the morphological characteristics of these $\mathrm{MnO}_{x}$ markedly affected their catalytic activity. Therefore, further establishing the super construction of $\mathrm{MnO}_{x}$ with carbonaceous substrates has potential for achieving cooperative merit to increase the electrocatalytic activity for the ORR. Recently, a series of works focused on $\mathrm{MnO}_{x}$ /graphene, and the electrochemical properties of these nanocomposites can be improved by adjustment in morphology. ${ }^{56,65-69}$

$\mathrm{MnO}_{2} /$ reduced graphene oxide $\left(\mathrm{MnO}_{2} / \mathrm{rGO}\right)$ nanocomposites were synthesized by a facile chemical reduction method assisted by poly(sodium 4-styrene sulfonate). There are two functional aspects of the polymer used in this synthesis. The first is aimed at increasing the solubility of graphene in aqueous solutions; the second is for tethering an $\mathrm{Mn}^{2+}$ precursor onto graphene. ${ }^{66}$ The polymer-assisted synthetic strategy is apt to create a 3D structure of $\mathrm{MnO}_{2} / \mathrm{rGO}$ nanocomposites, which possess good electrocatalytic activity toward the four-electron reduction of oxygen. Another $\mathrm{MnO}_{2} /$ graphene nanosheet $\left(\mathrm{MnO}_{2} / \mathrm{GNs}\right)$ hybrid was prepared under microwave irradiation. ${ }^{68}$ The prepared $\mathrm{MnO}_{2}$ particles (size of $\sim 5-10 \mathrm{~nm}$ ) were uniformly coated on the surface of GNs. The nanocomposites displayed a distinctive oxygen reduction peak at $-0.43 \mathrm{~V}$ in alkaline solution, which is more positive than that of $\mathrm{MnO} 2(-0.71 \mathrm{~V})$ and even better than that of $\mathrm{Pt} / \mathrm{C}(-0.44 \mathrm{~V})$, demonstrating that $\mathrm{MnO}_{2} / \mathrm{GNs}$ qualified as a significant ORR accelerator.

Bag and co-workers ${ }^{65}$ successfully synthesized nitrogendoped reduced graphene oxide (N-rGO) and $\mathrm{Mn}_{3} \mathrm{O}_{4}$ hybrid $\left(\mathrm{Mn}_{3} \mathrm{O}_{4} / \mathrm{N}-\mathrm{rGO}\right)$ by the one-step in situ reduction of both graphene oxide (GO) and $\mathrm{Mn}^{7+}$ by hydrazine (Fig. 6a), and the resulting functional electrocatalysts exhibit pronounced electrocatalytic activity towards ORR in alkaline solution. Fig. 6b illustrates that $\mathrm{Mn}_{3} \mathrm{O}_{4}$ nanospheres with an average size of $40 \mathrm{~nm}$ were randomly dispersed on wrinkled rGO sheets, with the legible exposure of the (112) plane of spinel 

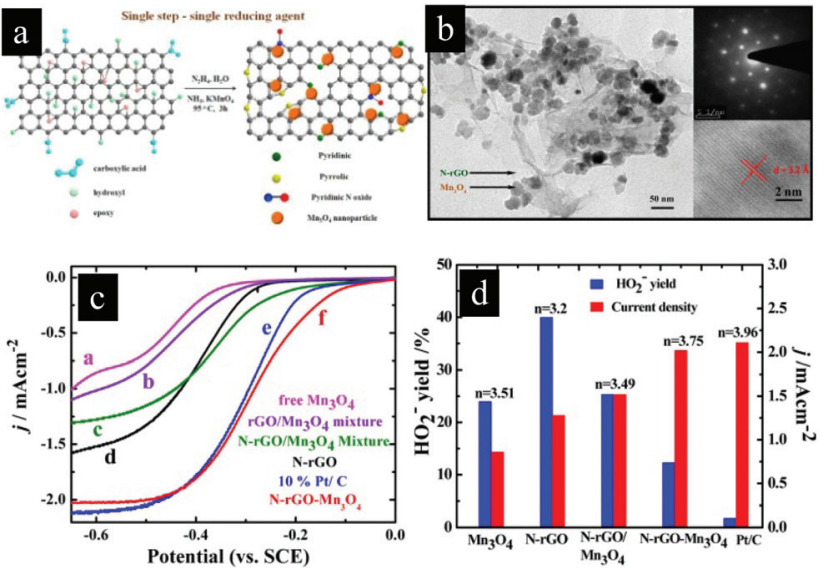

Fig. 6 (a) Scheme of one-pot synthesis of $\mathrm{N}-\mathrm{rGO}-\mathrm{Mn}_{3} \mathrm{O}_{4}$ hybrid material. (b) TEM images of the N-rGO- $\mathrm{Mn}_{3} \mathrm{O}_{4}$ hybrid material. (c) Polarization curves of the electrocatalytic performance of $\mathrm{N}-\mathrm{rGO}-\mathrm{Mn}_{3} \mathrm{O}_{4}$ and other synthesized catalysts towards ORR at $1600 \mathrm{rpm}$. (d) Plot illustrating the percentage of peroxide yield, current density and number of electrons transferred for all of the catalysts. Peroxide yield, current density and number of electrons were calculated using the ring/disk current at the potential of $-0.6 \mathrm{~V}$. Supporting electrolyte: $\mathrm{O}_{2}$ saturated $0.1 \mathrm{M} \mathrm{KOH}$. Scan rate: $5 \mathrm{mV} \mathrm{s}^{-1}$. Reproduced with permission from ref. 65 . Copyright ACS 2014.

$\mathrm{Mn}_{3} \mathrm{O}_{4}$ by identifying the fringe spacing of $0.32 \mathrm{~nm}$. As for the produced N-rGO- $\mathrm{Mn}_{3} \mathrm{O}_{4}$ hybrid, it showed a better onset potential for the reduction of oxygen at $-0.075 \mathrm{~V}$ than that of $\mathrm{rGO} /$ $\mathrm{Mn}_{3} \mathrm{O}_{4}, \mathrm{Pt} / \mathrm{C}$, and free $\mathrm{Mn}_{3} \mathrm{O}_{4}$. In addition, the corresponding current density of $\mathrm{N}-\mathrm{rGO}-\mathrm{Mn}_{3} \mathrm{O}_{4}$ at $-0.6 \mathrm{~V}$ was $2.0 \mathrm{~mA} \mathrm{~cm}{ }^{-2}$, which was 1.3-2.3 times higher than that of comparable catalysts and was close to that of Pt/C. As seen from Fig. 6d, the average electron transfer number of $\mathrm{N}-\mathrm{rGO}-\mathrm{Mn}_{3} \mathrm{O}_{4}$ for ORR was 3.75 , and the percentage of generated $\mathrm{HO}_{2}{ }^{-}$during ORR varied between $5 \%$ and $12.3 \%$ from -0.2 to $-0.6 \mathrm{~V}$, both implying its favorable four-electron pathway for ORR.

Various structural and morphological specificities of the $\mathrm{MnO}_{x}$-graphene nanocomposites have great influence on catalytic activity towards ORR in a $0.1 \mathrm{M} \mathrm{KOH}$ solution. Wu and coworkers ${ }^{69}$ synthesized $\mathrm{MnO}_{2}$ /graphene nanosheets $\left(\mathrm{MnO}_{2} /\right.$ GNs) composites with different crystallographic structures of $\mathrm{MnO}_{2}$ such as nanowires, amorphous nanoparticles, and microprisms. The diversity of the $3 \mathrm{D} \mathrm{MnO}_{2} / \mathrm{GNs}$ was theoretically generated under different heating times from 0 to $40 \mathrm{~h}$. The heat treatment promoted changes in crystalline phase from $\alpha$ - to $\beta-\mathrm{MnO}_{2}$. Fig. 7d depicts the linear sweep voltammetry (LSV) curves for ORR obtained at a bare glassy carbon (GC), $\mathrm{MnO}_{x}(0 \mathrm{~h}) / \mathrm{GC}, \mathrm{MnO}_{x}(4 \mathrm{~h}) / \mathrm{GC}$, and $\mathrm{MnO}_{x}(40 \mathrm{~h}) / \mathrm{GC}$ electrodes with a rotation rate of $800 \mathrm{rpm}$. The evident ORR activity of $\mathrm{MnO}_{x}(4 \mathrm{~h}) / \mathrm{GC}\left(\alpha-\mathrm{MnO}_{2}\right.$ nanowire) was obtained with the highest current density of $2.85 \mathrm{~mA} \mathrm{~cm}^{-2}$ at $-0.5 \mathrm{~V}$. The further introduction of $\alpha-\mathrm{MnO}_{2}$ nanowires on graphene enabled an approximate four-electron reduction of $\mathrm{O}_{2}$ reduction in alkaline solution. Furthermore, the decrease of current density was only $7.3 \%$ after electrocatalysis for 10000 s, suggesting the promising $\alpha-\mathrm{MnO}_{2} / \mathrm{GNs}$ cathodic catalysis of ORR.
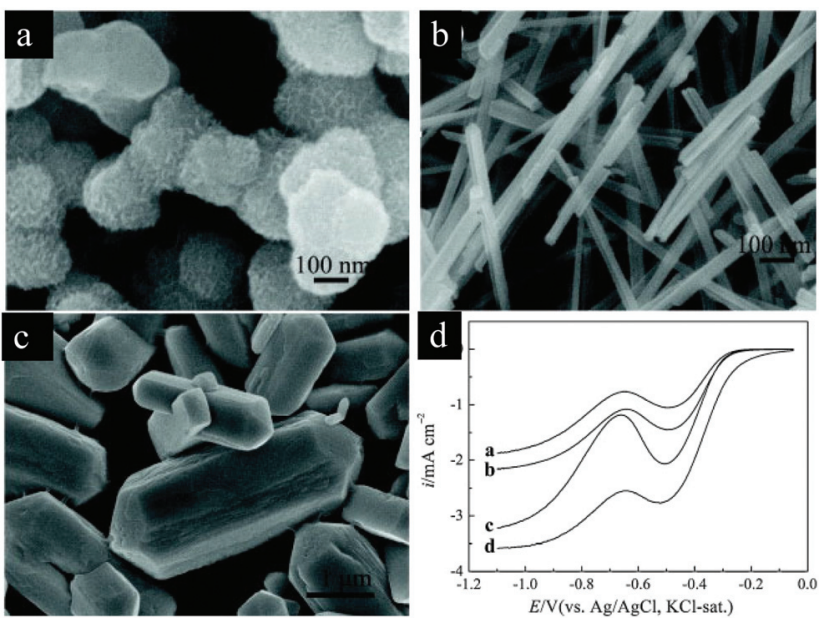

Fig. 7 SEM images of $\mathrm{MnO}_{x}$ prepared with different hydrothermal treatment times (a: $0 \mathrm{~h} ; \mathrm{b}: 4 \mathrm{~h} ; \mathrm{c}: 40 \mathrm{~h}$ ). (d) LSV curves recorded using a bare $\mathrm{GC}$ and $\mathrm{MnO}_{x}(0 \mathrm{~h}) / \mathrm{GC}, \mathrm{MnO}_{x}(4 \mathrm{~h}) / \mathrm{GC}$, and $\mathrm{MnO}_{x}(40 \mathrm{~h}) / \mathrm{GC}$ electrodes with a rotation rate of $800 \mathrm{rpm}$. Reproduced with permission from ref. 69. Copyright Elsevier 2012.

\subsection{Copper oxide $\left(\mathrm{CuO}_{x}\right)$}

Copper oxides (i.e., $\mathrm{CuO}$ and $\mathrm{Cu}_{2} \mathrm{O}$ ) were gradually paid more and more attention for its potential utilization in lithium ion batteries, ${ }^{70}$ wastewater treatment, ${ }^{71}$ and electrocatalysis of the ORR. ${ }^{72}$ The integration of $\mathrm{CuO}_{x}$ on carbonaceous materials to obtain enhanced properties for applications, such as stable catalytic activity of the ORR, are considered as efficient cathodes for practical applications. Thus, a copper oxide/nitrogendoped reduced graphene oxide ( $\mathrm{CuO} / \mathrm{N}-\mathrm{rGO})$ nanocomposite was synthesized through the aqueous coprecipitation method. ${ }^{73}$ The leaf-like CuO (average length of $100 \mathrm{~nm}$ and width of $15 \mathrm{~nm}$ ) was randomly loaded on N-rGO (Fig. 8a). The
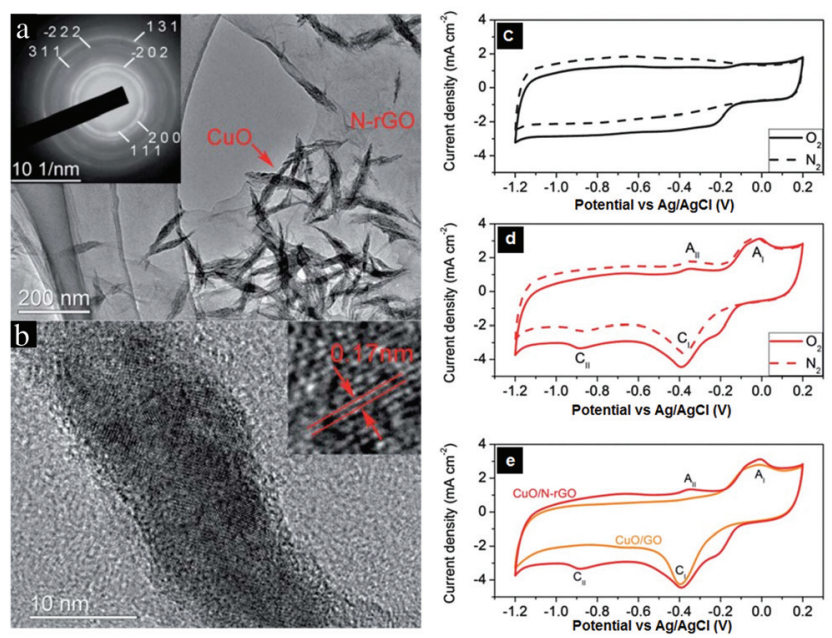

Fig. 8 (a) Low magnification TEM and selected area electron diffraction (inset) of the CuO/N-rGO. (b) High resolution TEM of a single CuO crystal. Its inset shows the lattice spacing of CuO. CV of N-rGO (c) and $\mathrm{CuO} / \mathrm{N}$-rGO (d) under $\mathrm{O}_{2}$-or $\mathrm{N}_{2}$-saturation $\left(0.1 \mathrm{~V} \mathrm{~s}^{-1}\right.$ ). (e) Comparison of $\mathrm{CV}$ of $\mathrm{CuO} / \mathrm{GO}$ and $\mathrm{CuO} / \mathrm{N}$-rGO $\left(\mathrm{O}_{2}\right.$-saturation, $\left.0.1 \mathrm{~V} \mathrm{~s}^{-1}\right)$. Reproduced with permission from ref. 73. Copyright RSC 2013. 
lattice spacing, illustrated in the inset of Fig. $8 \mathrm{~b}$, was $0.17 \mathrm{~nm}$, demonstrating the crystal growth of well-structured $\mathrm{CuO}(020)$ plates supported on N-rGO. Compared with Fig. $8 \mathrm{c}$ and d, $\mathrm{CuO} / \mathrm{N}-\mathrm{rGO}$ not only performed a distinct oxygen reduction peak at $-0.39 \mathrm{~V}$ under an $\mathrm{O}_{2}$-saturated solution, but also had a higher current density of ORR than $\mathrm{CuO} / \mathrm{GO}$ catalysts. Another $\mathrm{Cu}_{2} \mathrm{O} / \mathrm{rGO}$ composite was synthesized via a twostep route, including the adequate mixing of copper acetate and graphite oxide and thermal reduction using diethylene glycol (DEG) for $2 \mathrm{~h}^{74}$ The calculated transferred electron number ranged from 3.2 to 3.6 at -0.4 to $-1.0 \mathrm{~V}$ and gradually increased along with a more negative potential. The authors further confirmed that the $\mathrm{Cu}_{2} \mathrm{O} / \mathrm{rGO}$ nanocomposites had a superior tolerance to methanol crossover and $\mathrm{CO}$ poisoning, revealing that the perspective application of $\mathrm{Cu}_{2} \mathrm{O} / \mathrm{rGO}$ as noble metal-free cathode catalysts in fuel cells was of great importance.

\subsection{Other transition metal oxides}

There are several studies on GNs-supported other transition metal oxides with applications as efficient cathode for the ORR. The structural interactions between graphene and tita- nium (Ti) are energetically more favorable for induced $\mathrm{p}-\mathrm{d}$ hybridization, which occurs between atomic carbon and titanium orbitals, and results in a short-range ordered crystalline deposition. ${ }^{75,76}$ Titanium dioxide nanospheres functionalized graphene sheets $\left(\mathrm{TiO}_{2}\right.$-FGSs) supported onto a nano-sized Pt catalyst was synthesized and utilized for electrocatalytic activity for ORR. ${ }^{77}$ The introduction of Pt on $\mathrm{TiO}_{2}$-FGSs stretched the nano size to $11 \pm 2 \mathrm{~nm}$. The excellent CV and RDE measurements of $\mathrm{TiO}_{2}$-FGSs both implied the superior and active ORR performance, and the oxygen reduction reaction based on $\mathrm{TiO}_{2}$-FGSs predominantly followed a $4 \mathrm{e}^{-}$pathway. In addition, nickel and cobalt oxides-graphene $\left(\mathrm{NiCoO}_{x} / \mathrm{GNs}\right)$ nanocomposites have been investigated by Elzatahry and co-workers by aqueous chemical reduction method. ${ }^{141}$ The produced catalysts displayed electrocatalytic activity for the methanol oxidation reaction (MOF) in acidic solution compared to Pt. The Mn and Co co-substituted $\mathrm{Fe}_{3} \mathrm{O}_{4}(\mathrm{Mn}: \mathrm{Co}: \mathrm{Fe}=1: 1: 1)$ nanoparticles on nitrogen doped reduced graphene oxide (N-rGO) nanosheets were synthesized by a hydrothermal method. ${ }^{78}$ The prepared catalysts exhibited comparable ORR activity with Pt/C ( 80\%). These summarized examples of graphene based transition metal oxide nanocomposites are listed in Table 1.

Table 1 Graphene based transition metal oxide nanocomposites and their applications

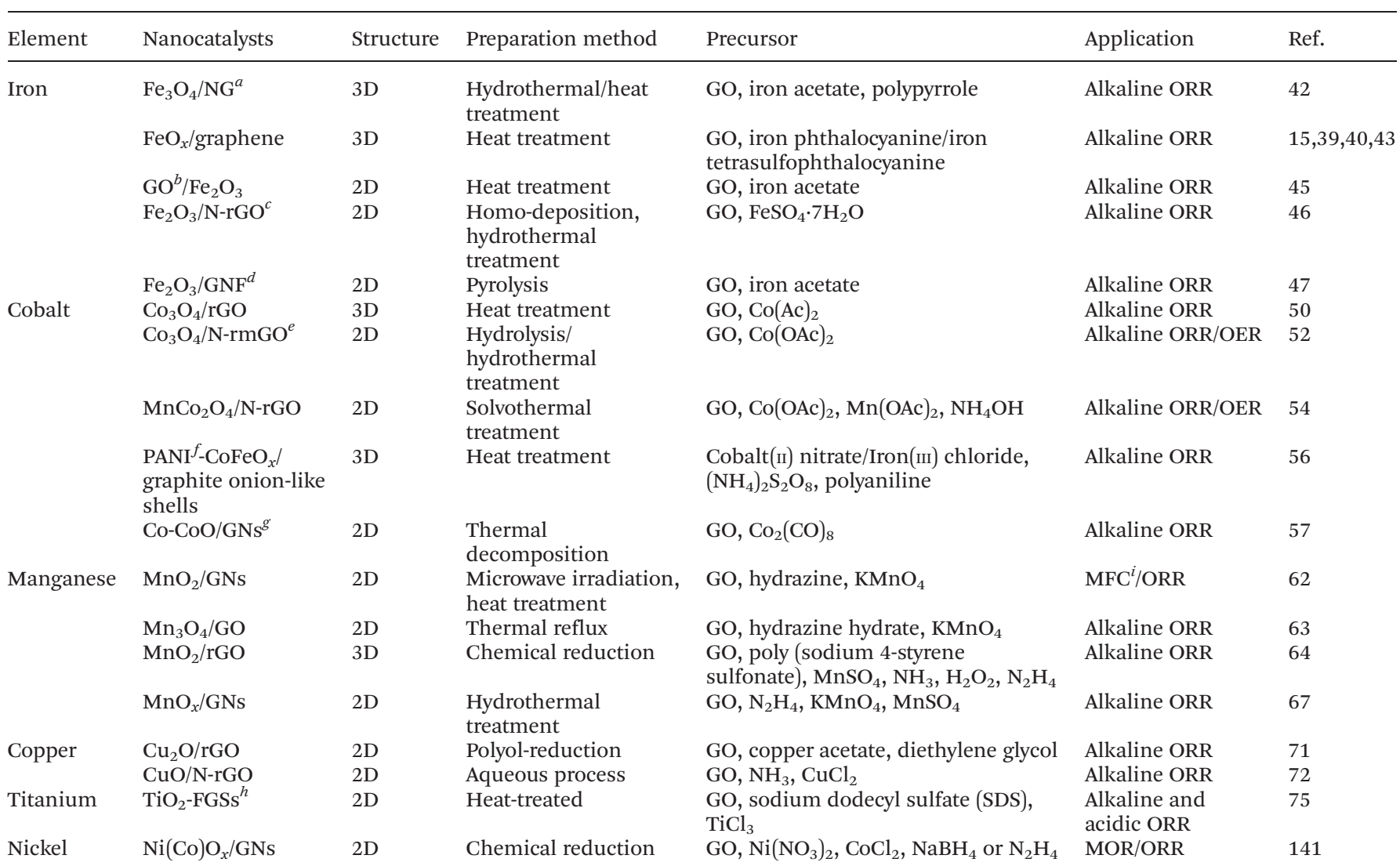

${ }^{a}$ NG: nitrogen-doped graphene. ${ }^{b} \mathrm{GO}$ : graphene oxides. ${ }^{c} \mathrm{~N}$-rGO: nitrogen doped reduced graphene oxides. ${ }^{d}$ GNF: graphene nano-flake. ${ }^{e} \mathrm{~N}$-rmGO: nitrogen doped reduced and mildly oxidized graphene. ${ }^{f}$ PANI: polyaniline. ${ }^{g}$ GNs: graphene nanosheets. ${ }^{h}$ FGSs: functionalized graphene nanosheets. ${ }^{i}$ MFC: microbial fuel cell. 


\section{Structural and electrocatalytic characterization of graphene-based transition metal oxides}

\subsection{Structural characterization}

As mentioned above, the nano size, composition, morphology, and surface property of synthesized nanocomposites have great effect on the catalytic activity of ORR; thus, exact, detailed, and clear structural characterizations are necessary to reveal the relations between microstructure and catalytic activity. The fundamental understanding of the structural characteristic of a nanocomposite is significant for building an optimal nanocatalyst to maximize the electroactivity of ORR. On the other hand, based on the sufficient characterizations of a nanocatalyst, the subsequent electrocatalytic characterization can essentially and directly depict its electrocatalytic performance, which can also give feedback on the further modification of catalysts. In this section, we briefly summarize the conventional techniques in ORR, particularly for structural characterization of graphene-supported transition metal oxides nanocomposites such as the compositional and crystalline characterization methods, which include X-Ray diffraction (XRD), X-ray photoelectron spectroscopy (XPS) and energy dispersive X-ray spectroscopy (EDX), morphological characterization techniques, which include transmission electron microscopy (TEM), high resolution transmission electron microscopy (HRTEM), and scanning electron microscopy (SEM), and thermal gravity analysis (TGA).

X-ray diffraction (XRD). An XRD pattern is generally applied to illustrate the typical crystalline peaks and evaluate the crystal size of nanocomposites according to the Scherrer equation. ${ }^{79,80}$ For instance, the nanoparticles of synthesized $\mathrm{Fe}_{2} \mathrm{O}_{3}$ on nitrogen-doped graphene were initially analyzed by XRD characterization. ${ }^{47}$ Some distinct and sharp diffraction peaks of the prepared nanocomposites were observed at $33.2^{\circ}$, $35.6^{\circ}, 49.4^{\circ}, 54.1^{\circ}, 62.4^{\circ}$, and $64.0^{\circ}$. Compared to the typical peaks of N-rGO (a flat and wide peak at $\sim 26^{\circ}$ ) and the standard powder diffraction file (PDF) of $\mathrm{Fe}_{2} \mathrm{O}_{3}$, it was found that the typical peaks of the synthesized nanocomposites were wellcrystallized by the growth of $\mathrm{Fe}_{2} \mathrm{O}_{3}$ on N-rGO with high purity and crystallinity. In addition, the XRD pattern of the nanocomposite exhibited a series of plane peaks, which can be ascribed to (012), (104), (110), (214), (300), (119), and (220) crystal planes of synthesized hematite (JCP DS no. 33-0664). Sometimes, the well-structured lattice spacing of nanocrystals also can be calculated from XRD data by referring to the Bragg equation. ${ }^{81-83}$

X-ray photoelectron spectroscopy (XPS). XPS is a meaningful device to investigate the chemical composition, element states, and the nature of heteroatom functionalized or doped graphene supported nanocomposites. As for the chemical composition of nanocomposites, XPS can reveal the nanoscale of nanocomposites in detail. For example, mutli-metallic introduced or heteroatom functionalized graphene should be strictly identified by XPS. Sun and co-workers used $\mathrm{AgNO}_{3}$ and
$\mathrm{KMnO}_{4}$ as the precursors and Vulcan (XC-72, $S_{\mathrm{BET}}=250 \mathrm{~m}^{2}$ $\left.\mathrm{g}^{-1}\right)$ as supports to synthesize $\mathrm{Ag}-\mathrm{MnO}_{x} / \mathrm{C}$ nanocomposites. ${ }^{84}$ The XPS results clearly identified the pure chemical composition of silver, manganese, and carbon, avoiding the disturbance of nitrogen doping on graphene. On the other hand, the heteroatom functionalized graphene may significantly elevate catalytic activity compared to native graphene. The nitrogendoped graphene is a category of graphene with a replaced $\mathrm{sp}^{2}$ bonded carbon atom with heteroatom nitrogen, which can be considered as an accelerator of the reduction of $\mathrm{O}_{2}$ to $\mathrm{H}_{2} \mathrm{O}$, which is facilitated on the in-plane $\mathrm{C}$ atom adjacent to the substitutional $\mathrm{N}$ atom. ${ }^{39,85}$ The reported facile single-step synthesis of a nitrogen-doped reduced graphene oxide- $\mathrm{Mn}_{3} \mathrm{O}_{4}$ hybrid was characterized by XPS. ${ }^{65}$ As seen from Fig. 9b, the deconvoluted analysis of $\mathrm{N}_{1 \mathrm{~s}}$ at binding energies from 396 to $404 \mathrm{eV}$, suggests the desirable doping of $\mathrm{N}$ to graphene. In addition, for the superficial chemistry exploration of nanocomposites, XPS can also provide important resources and proof. In a recent work, the oxidation states of Ir and carbon of $\operatorname{~rr}_{2} \mathrm{~V}$ nanoclusters supported on rGO nanosheets were studied by XPS measurements. ${ }^{86}$ The $\operatorname{Ir}_{4 \mathrm{f} 7 / 2}$ and $\operatorname{Ir}_{4 \mathrm{f} 5 / 2}$ of $\operatorname{Ir}^{0}$ shifted from 60.90 and $63.90 \mathrm{eV}$ on $\mathrm{Ir} / \mathrm{rGO}$ to 61.43 and $64.35 \mathrm{eV}$ on $\operatorname{Ir}_{2} \mathrm{~V} /$ rGO, indicating not only the transformation of valence state from Ir to $\operatorname{Ir}_{2} \mathrm{~V}$, but also electron transfer from Ir to $\mathrm{V}$.

Raman and Fourier transform infrared spectroscopy (FTIR). FTIR spectroscopy is used to probe molecular vibrations by the absorption of partial visible light $\left(4000 \mathrm{~cm}^{-1}\right.$ to $\left.400 \mathrm{~cm}^{-1}\right)$. Groups with specific chemical bonds (such as hydroxyl, carbonyl, carboxylic, and epoxy) absorb light energy and is inherently illuminated with a frequency corresponding to the fundamental vibration. ${ }^{87}$ Raman spectroscopy measures the frequencies of Raman-scattered monochromatic light. In fact, Raman spectroscopy provides sufficient chemical information, which is supplementary to FTIR. The integrated characterization of nanocomposites both by Raman and FTIR is efficient in detecting the group vibrations in polar/non-polar mole-
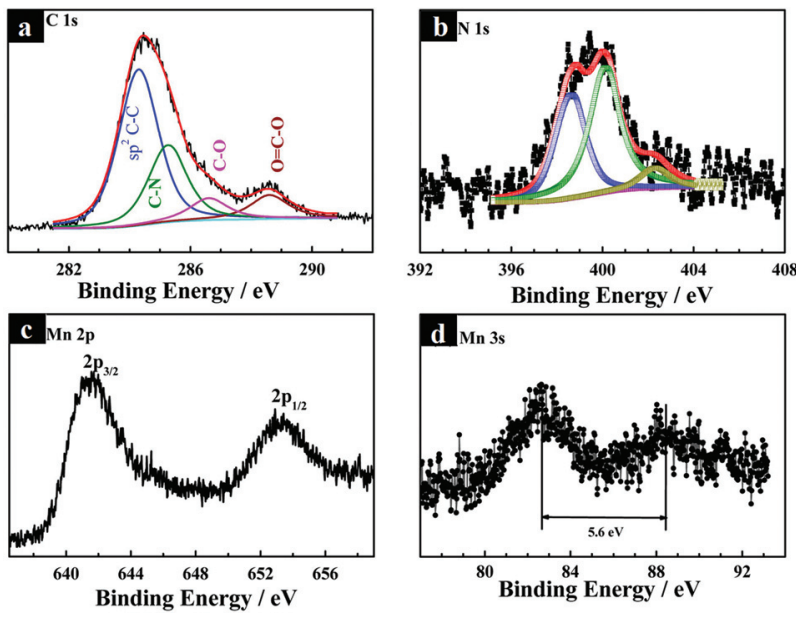

Fig. 9 Deconvoluted XPS profile of a $\mathrm{N}-\mathrm{rGO}-\mathrm{Mn}_{3} \mathrm{O}_{4}$ hybrid material: (a) $\mathrm{C}_{1 \mathrm{~s}}$ (b) $\mathrm{N}_{1 \mathrm{~s}}$, (c) $\mathrm{Mn}_{2 \mathrm{p}}$, and (d) $\mathrm{Mn}_{3 \mathrm{~s}}$. Reproduced with permission from ref. 65. Copyright ACS 2014. 
cules. ${ }^{88}$ In a typical Raman spectrum of carbon atoms in graphene sheets, three typical peaks of the $\mathrm{G}$ band at around $1580 \mathrm{~cm}^{-1}$, the D band at around $1350 \mathrm{~cm}^{-1}$, and the $2 \mathrm{D}$ band at $2700 \mathrm{~cm}^{-1}$ can be detected. The $\mathrm{G}$ band represents $\mathrm{sp}^{2}$ carbon atoms domains; the $\mathrm{D}$ is generally related to the vibrations of $\mathrm{sp}^{3}$ carbon atoms; the $2 \mathrm{D}$-band is sensitive to the layers of graphene sheets. As shown in Fig. 10a, in addition to the $\mathrm{D}$ and $\mathrm{G}$ bands, prominent peaks at 571 and $633 \mathrm{~cm}^{-1}$ can be ascribed to the (Mn-O) stretching vibration, thus revealing the fabrication of $3 \mathrm{D}$ graphene with $\mathrm{MnO}_{2} \cdot{ }^{64}$ Moreover, the intensity ratio of the $\mathrm{D}$ band and $\mathrm{G}$ band demonstrates the density of structure defects on the surface of graphene. For instance, the Raman pattern of nitrogen-doped grapheneultrathin $\mathrm{MnO}_{2}$ sheet composites (NGMCs) revealed a higher intensity ratio of the $\mathrm{D}$ and $\mathrm{G}$ band $\left(I_{\mathrm{D}} / I_{\mathrm{G}}\right)(1.09)$ than the pristine graphene (0.66), which has potential for improving the catalytic activity of the ORR due to the increased active sites provided by more defects on the NGMCs. ${ }^{89}$ Fig. 10c shows the FTIR patterns of GO and Ni@Pd/graphene. Firstly, the main peaks of hydroxyl at $3448 \mathrm{~cm}^{-1}$, methyl at around 2973 and $2338 \mathrm{~cm}^{-1}$, and carboxyl groups at $1702 \mathrm{~cm}^{-1}$ were clearly confirmed due to the overoxidation of graphene. ${ }^{90,91}$ However, the intensity of the peak at $3448 \mathrm{~cm}^{-1}$ on Ni@Pd nanoparticles (green line) decreased owing to the decline of $-\mathrm{OH}$; moreover, the other main oxygen-contained functional groups attenuated distinctly, suggesting that the anchoring of Ni@Pd nanoparticles on graphene was combined with the functional groups. Furthermore, the analysis of the Raman spectra further confirmed the significant reduction of the $\mathrm{D}$ band, but the enhancement of the $\mathrm{G}$ band on Ni@Pd/graphene, which is primarily due to metal-carbon interactions. ${ }^{92}$ In general, comprehensive analysis of both FTIR and Raman spectroscopy is
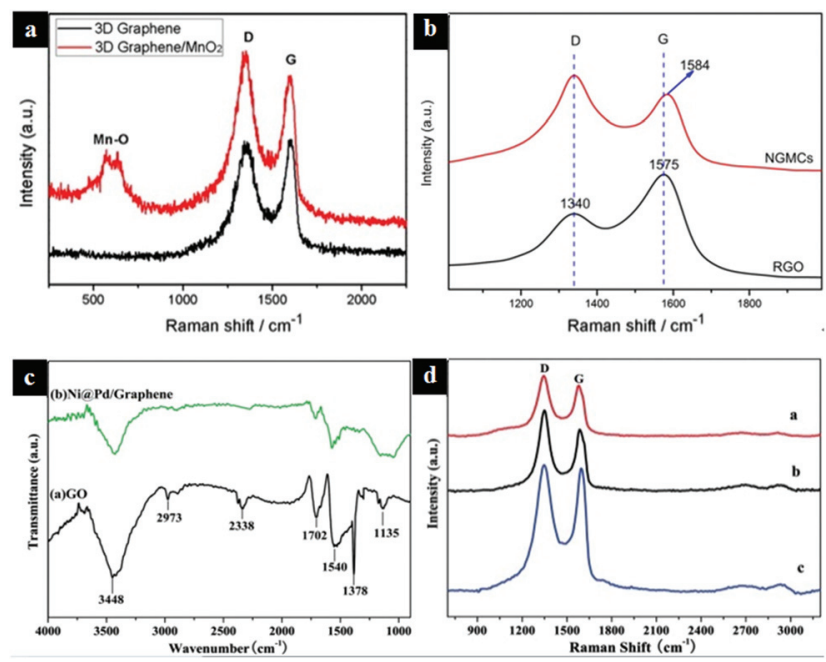

Fig. 10 (a) Raman spectra of 3D graphene and 3D graphene/ $\mathrm{MnO}_{2}$. (b) Raman spectra of NGMCs with 2.77 at\% doping level and RGO. (c) FTIR spectra of GO and NiaPd/graphene. (d) Raman spectra of GO, Ni/ graphene, and Ni@Pd/graphene. Reproduced with permission from ref. 64. Copyright ACS 2014; from ref. 89. Copyright ACS 2013; from ref. 92. Copyright RSC 2012. beneficial for completely understanding the chemical and crystalline information of synthesized nanocomposites.

Morphological characterization (TEM, HRTEM, and SEM). The morphological and structural features of nanoparticles have a great effect on their electronic and catalytic properties. In particular, for the transition metal oxides supported on graphene nanocomposites, the control of the particle sizes and exposed active facets are of importance for increasing the contact efficiency between particles and oxygen and accelerating electron transfer among metal oxides, graphene and oxygen. Nevertheless, ordinary electronic microscopes are unlikely to fulfill the role for this kind of microscopic image processing. Transmission electron microscopy (TEM) and scanning electron microscopy (SEM) are able to directly obtain the morphology and structural information of the supported transition metal oxides and graphene nanosheets.

Scanning electron microscopy (SEM) is generally applied to describe the overall configuration of nanocomposites at large scales from several microns to $500 \mathrm{~nm}$. In order to obtain clear images within the nanoscale or even smaller, TEM and HRTEM are suitable to provide a considerably more comprehensive and descriptive view of nanocomposites from the microstructure of transition metal oxides and the crystal lattice arrangement or defects on graphene sheets. ${ }^{93,94}$ For example, Fig. 11 shows the high resolution TEM images processed with an FFT bandpass filter of a suspended single layer of graphene, GO, and reduced and annealed graphene oxide (raGO) ${ }^{95}$ The perfect "honeycomb" lattice of graphene could be seen by HRTEM in 2 nanometers (Fig. 11a). The large area (in purple) of functionalization of oxygen-contained groups dominated; moreover, the blue holes, which emerged on the GO nanosheet, were considered as the defects due to the release of $\mathrm{CO}$ or $\mathrm{CO}_{2}$ during overoxidation and exfoliation. Moreover, the authors further found that the average area of the holes on GO was less than $5 \mathrm{~nm}^{2}$. After the reduction and annealing of GO, the resulting raGO presented a large area hole compared to GO, which can be clearly observed through the HRTEM image (Fig. 11c). Fig. 11d and e show the high resolution images same as Fig. 11a-c, but show an enlarged region of the micrographs of appointed defects. A proposed possible model of the structure for the region of oxygencontaining groups and nitrogen-contained defects were established, and the simulated HRTEM image for the abovementioned proposed structure was finally designed. Although the TEM and HRTEM can well enlarge the micro view into one nanometer, there is still around a $0.2 \mathrm{~nm}$ size limitation for TEM and HRTEM. More importantly, electron beam heating could destroy tiny nanoparticles; therefore, the effect of particle melting during imaging cannot be neglected.

Other electron microscopy characterization methods (STEM, AFM and STM). Scanning transmission electron microscopy (STEM) integrates the advantages of SEM and TEM and has wide applications in the characterization of morphology, crystal structure of nano materials. Song et al. ${ }^{96}$ photographed free-standing graphene sheets by STEM and found that an accurate calibration of the STEM intensity of discrete numbers 

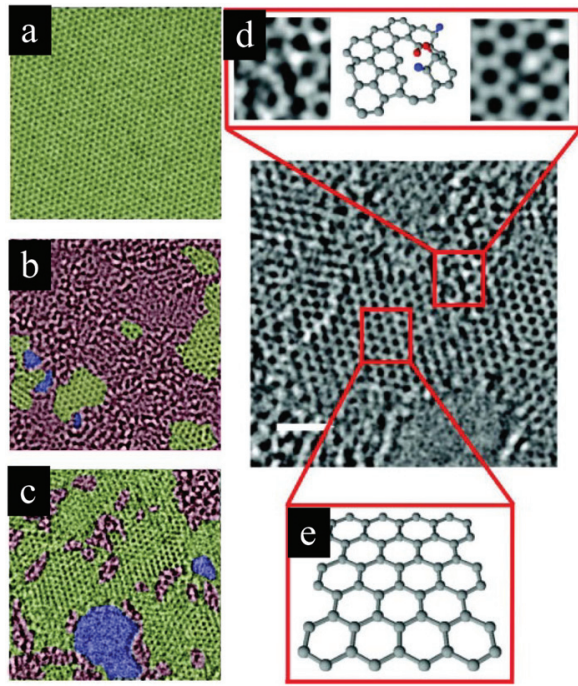

Fig. 11 Aberration corrected TEM images of (a) Single suspended sheet of graphene indicated in yellow. (b) Single suspended sheet of GO. (c) Suspended monolayer of raGO. The holes are indicated in blue, graphitic areas in yellow and high contrast, disordered regions, indicating oxygen functionalities, in purple. Aberration-corrected TEM image of a monolayer of raGO. Expansion (d) shows an enlarged region of the micrograph, a proposed possible structure for the region where oxygen (indicated in purple) and nitrogen (blue) remain as functionalities on the sheets, and finally a simulated TEM image for this proposed structure (from left to right). Expansion (e) shows the structure of a graphitic region. Scale bar, denoting 2 nanometers, is valid for all images. Reproduced with permission from ref. 95. Copyright Wiley 2010.

of graphene layers can exhibit stretched thickness with an ultra-sensitivity of a single atomic layer. Atomic force microscopy (AFM) and scanning tunneling microscopy (STM), as scanning probe techniques, play a vital role in the structural characterization of solid surfaces with atomic resolution. It is reported that the thickness of monolayer graphene is approximate $0.34 \mathrm{~nm}$, but the thickness of a single layer of functionalized GO can be detected to be 1 to $1.5 \mathrm{~nm}$ by AFM analysis. ${ }^{97-99}$ Practically, AFM partially provides layer information, and it is better to associate it with Raman and XPS measurements for a full understanding of facial chemical information. In addition, STM is another efficient electron microscopy technique used to obtain the lattice structure, surface morphology, particle size and distribution of graphene-based materials surface at atomic resolution. ${ }^{97,100,101}$

As shown in Fig. 12, the overview of uniform and folded graphene nanosheets colored by a blue shade was imaged by STEM in $200 \mathrm{kV}$ with a high angle annular dark field (HAADF) detector. Fig. 12b and c display the 3 and 28 layers of graphene edges corresponding to the two areas with arrows pointing in Fig. 12a. ${ }^{96}$ Mono-, bi-, and tri-layers of graphene can be readily identified by AFM measurements (Fig. 12d). These stacked layers can be attributed to the nature of graphene. Fig. 12e shows the histograms of the AFM-depth profiles. From the quantitative analysis of flake height, the thickness of a single sheet was $\sim 1.6 \mathrm{~nm}$ and the ratio of thicknesses of the mono-, bi-, and tri-layers scale was $1: 1.6: 2.2 .{ }^{94}$

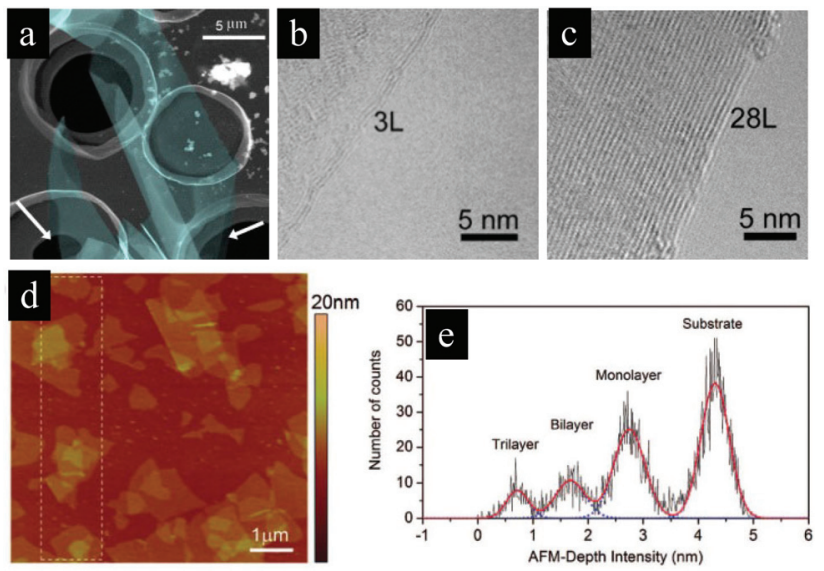

Fig. 12 (a) HAADF-STEM image showing an overview of graphene flakes supported by a holey Formvar film covered with $\mathrm{Cu}$ grids. The arrows indicate areas where graphene is freely suspended on the holey film. (b) High resolution TEM images of a 3 layered graphene edge. (c) High resolution TEM images of a 28 layered graphene edge. (d) AFM image of the GO films where mono-, bi-, and tri-layers of GO films can be identified. (e) Histogram of the AFM-depth intensities obtained from the dotted area of image $\mathrm{d}$. The histogram is fitted with a linear combination of four Gaussian functions representing each peak. Reproduced with permission from ref. 96. Copyright Elsevier 2010. Reproduced with permission from ref. 94. Copyright ACS 2009.

Other characterization methods (UV-Vis, EELS, EDX and TGA). There are some other techniques used to characterize nanocomposites from the surface chemistry to the inside crystal structure. In this part, we will briefly introduce these characterization methods. The typical UV-vis absorption peaks of graphene and graphene oxide are at around 268, 230 and $300 \mathrm{~nm}$, which is relevant to the linear growth of the thickness of graphene nanosheets, the $\pi-\pi^{*}$ transitions of aromatic $\mathrm{C}=\mathrm{C}$ bonds, and the $n-\pi^{*}$ transitions of $\mathrm{C}=\mathrm{O}$ bonds, respectively. ${ }^{102}$ Electron energy loss spectroscopy (EELS) is efficiently used for measuring the electronic properties of graphene-based nanomaterials. Cooperating with STEM, EELS can exhibit superior performance in identifying the individual heteroatom functionalized chemistry and electronic structure of graphene. ${ }^{103,104}$ As for energy dispersive X-ray (EDX) spectroscopy, it can qualitatively and quantitatively analyze the element distribution on graphene-based materials. For mono-, bi-, and multi-metal oxides supported on graphene sheets, EDX is effective for compositional determination of the nanocomposites combined with TEM or SEM. ${ }^{105,106}$ Thermogravimetric analysis (TGA) is a widely used technique to characterize the thermal stability and the loading amount of a metal in graphene-based composites. ${ }^{107-109}$

\subsection{Electrocatalytic ORR characterization}

The electrocatalytic property of ORR can be characterized by a series of electrochemical methods and devices, such as cyclic voltammograms (CV) measurements, linear sweep voltammetry analysis (LSV), electrochemical impedance spectroscopy (EIS), and rotating-disk electrodes (RDE) and rotating ring-disk 
electrodes (RRDE). Each method has their specific advantages in describing the ORR performance of a catalyst with the corresponding expression, parameters and calculations. Evidently, the characterization of the ORR by only one or two methods mentioned above is insufficient and incomplete. Thus, in this section, we will introduce these electrocatalytic ORR characterizations and their specialties, to guide a comprehensive description of ORR activity of graphene-based transition metal oxide nanocomposites.

Cyclic voltammograms measurement (CV). CV measurement is the most authoritative and convincing method to examine the ORR activity of nanocomposites. CV is generally performed in an $\mathrm{O}_{2}$-saturated $0.1 \mathrm{M} \mathrm{KOH}$ solution at room temperature. The electrochemical cell contains three electrodes: a working glassy carbon electrode (GCE) coated with a quantitative catalyst, a $\mathrm{Ag} \mid \mathrm{AgCl} / \mathrm{KCl}$ (saturated) reference electrode and Pt wire as a counter electrode. After that, the tested working electrode should cycle in a potential range within a scan rate $\sim 50 \mathrm{mV} \mathrm{s}^{-1}$ for an entire cycle.

As shown in Fig. 13a, the commercial Pt/C shows typical CVs curves of ORR in $\mathrm{N}_{2}$ and $\mathrm{O}_{2}$-saturated $0.1 \mathrm{M} \mathrm{KOH}$. The black dash line represents the response of current densities in the $\mathrm{N}_{2}$-saturated $0.1 \mathrm{M} \mathrm{KOH}$ at potentials ranging from 0.36 to $1.1 \mathrm{~V}$. It is evident that there was no peak appearing at $\sim 0.9 \mathrm{~V}$, which is widely accepted as the typical ORR peak of $\mathrm{Pt} / \mathrm{C} .^{55}$ However, the response of current densities in the $\mathrm{O}_{2}$-saturated $0.1 \mathrm{M} \mathrm{KOH}$ (red line) exhibited a distinct performance of ORR. The significant peak of ORR at the potential of $\sim 0.9 \mathrm{~V}$ of $\mathrm{Pt} / \mathrm{C}$

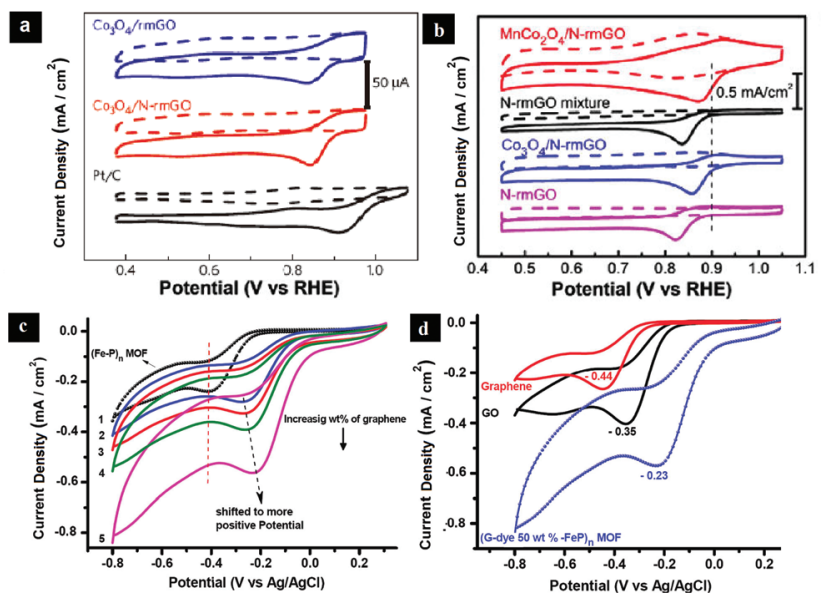

Fig. 13 (a) $\mathrm{CVs}$ of ORR on Pt/C electrodes in $\mathrm{N}_{2}$ - and $\mathrm{O}_{2}$-saturated 0.1 $\mathrm{M} \mathrm{KOH}$ at a scan rate of $10 \mathrm{mV} \mathrm{s}^{-1}$. (b) CV curves of $\mathrm{MnCo}_{2} \mathrm{O}_{4} / \mathrm{N}-\mathrm{rmGO}$, $\mathrm{MnCo}_{2} \mathrm{O}_{4}+\mathrm{N}$-rmGO mixture, $\mathrm{CO}_{3} \mathrm{O}_{4} / \mathrm{N}-\mathrm{rmGO}$, and $\mathrm{N}$-rmGO on glassy carbon electrodes in $\mathrm{O}_{2}$-saturated (solid line) or $\mathrm{N}_{2}$-saturated (dash line) $1 \mathrm{M} \mathrm{KOH}$. The peak position of $\mathrm{Pt} / \mathrm{C}$ is shown as a dashed line for comparison. (c) CVs of oxygen reduction on the (Fe-P) $n$ MOF, (2) (G-dye 5 wt $\%-F e P)_{n}$ MOF, (3) (G-dye 10 wt\% -FeP) $n$ MOF, (4) (G-dye 25 wt\% -FeP) $)_{n}$ MOF, (5) (G-dye 50 wt\% -FeP) $n$ MOF electrodes obtained in $\mathrm{O}_{2}$ saturated $0.1 \mathrm{M} \mathrm{KOH}$ at a scan rate of $50 \mathrm{mV} \mathrm{s}^{-1}$. (d) $\mathrm{CVs}$ of oxygen reduction on exfoliated graphene, GO, (G-dye $50 \mathrm{wt} \%$-FeP) $n$ MOF electrodes in $0.1 \mathrm{M} \mathrm{KOH} \mathrm{O}_{2}$-saturated at a scan rate of $50 \mathrm{mV} \mathrm{s}^{-1}$. Reproduced with permission from ref. 55. Copyright ACS 2014; from ref. 56. Copyright ACS 2013; from ref. 110. Copyright ACS 2012. can be observed, suggesting the excellent ORR activity of $\mathrm{Pt} / \mathrm{C}$ with its standard onset potential $(\sim 1.0 \mathrm{~V})$ and peak potential $(\sim 0.9 \mathrm{~V})$. Fig. 13b shows the electrocatalytic ORR properties of $\mathrm{MnCo}_{2} \mathrm{O}_{4} / \mathrm{N}$-rmGO $\left(\mathrm{MnCo}_{2} \mathrm{O}_{4}\right.$ supported N-doped reduced mildly oxidized graphene oxide), $\mathrm{N}$-rmGO mixture, $\mathrm{Co}_{3} \mathrm{O}_{4} /$ $\mathrm{N}$-rmGO and $\mathrm{N}$-rmGO in a $\mathrm{N}_{2}$ - and an $\mathrm{O}_{2}$-saturated $0.1 \mathrm{M} \mathrm{KOH}$ electrolyte solution. In contrast, when the electrolyte was saturated with $\mathrm{O}_{2}$, the four electrodes displayed different performances for $\mathrm{O}_{2}$ reduction. The ORR activity of $\mathrm{MnCo}_{2} \mathrm{O}_{4} / \mathrm{N}-\mathrm{rmGO}$ (red line) significantly showed a more positive peak potential and higher peak current density $\left(0.88 \mathrm{~V}, 0.5 \mathrm{~mA} \mathrm{~cm}{ }^{-2}\right)$ than that of the N-rmGO mixture $\left(\sim 0.84 \mathrm{~V}, 0.38 \mathrm{~mA} \mathrm{~cm}{ }^{-2}\right), \mathrm{Co}_{3} \mathrm{O}_{4} /$ N-rmGO $\left.(\sim 0.86 \mathrm{~V}, 0.44 \mathrm{~mA} \mathrm{~cm})^{-2}\right)$ and N-rmGO $(\sim 0.82 \mathrm{~V}$, $0.29 \mathrm{~mA} \mathrm{~cm}^{-2}$ ), but still smaller than that of commercial $\mathrm{Pt} / \mathrm{C}$ (the vertical dash line is marked as the peak potential of $\mathrm{Pt} / \mathrm{C}$ ), suggesting a promising ORR activity of $\mathrm{MnCo}_{2} \mathrm{O}_{4} / \mathrm{N}-\mathrm{rmGO}$. In addition, the onset potential decreased in the sequence: $\mathrm{Pt} / \mathrm{C}>$ $\mathrm{MnCo}_{2} \mathrm{O}_{4} / \mathrm{N}$-rmGO $>\mathrm{Co}_{3} \mathrm{O}_{4} / \mathrm{N}-\mathrm{rmGO}>\mathrm{N}$-rmGO mixture > $\mathrm{N}$-rmGO, further implying a weak ORR capacity of N-rmGO compared to $\mathrm{MnCo}_{2} \mathrm{O}_{4} / \mathrm{N}-\mathrm{rmGO}, \mathrm{Co}_{3} \mathrm{O}_{4} / \mathrm{N}-\mathrm{rmGO}$ and $\mathrm{Pt} / \mathrm{C} .^{56}$ Fig. 13c illustrates the distinctive characterization of CVs towards different electrodes during the ORR process. Lines 1 to 5 represent the different synthesized electrodes with increasing composition of G-dye in the MOF composites. Evidently, the peak potential, onset potential and peak current density for the ORR from 1 to 5 are gradually shifted to more positive locations, suggesting that the (G-dye $50 \mathrm{wt} \%-\mathrm{FeP})_{n}$ MOF electrodes had the most superior ORR due to its better electron transfer properties and electrochemical surface area. ${ }^{110}$ The ORR activity of the (G-dye $50 \mathrm{wt} \%-\mathrm{FeP})_{n} \mathrm{MOF}$, GO and exfoliated graphite are shown in Fig. 13d. It can be seen that GO had more electroactivity of the ORR compared to graphite owing to the positive shift of the peak potential of $90 \mathrm{mV}$ and the increase in the current density of $0.2 \mathrm{~mA} \mathrm{~cm}^{-2}$. Moreover, the peak and onset potential of the (G-dye $50 \mathrm{wt} \%-\mathrm{FeP})_{n} \mathrm{MOF}$ cathode shifted increasingly by about $120 \mathrm{mV}$ compared with GO and exhibited an excellent ORR peak current density of $0.6 \mathrm{~mA} \mathrm{~cm}^{-2}$, which was the highest among the three samples. The authors attributed this improvement of ORR to the synthesis strategy of synergistic framework porosity, a larger bond polarity and the catalytically active iron-porphyrin.

In conclusion, the $\mathrm{CV}$ measurement is most commonly used method for describing the ORR activity of synthesized nanomaterials. Generally, the important parameters for the identification of the efficiency of $\mathrm{O}_{2}$ reduction can be listed as follows. (1) The onset potential of CV means the sensitivity of $\mathrm{O}_{2}$ reduction reaction of cathodes, a more positive onset potential demonstrates the better response of the electrochemical reduction of $\mathrm{O}_{2}$. (2) Peak potential represents the typical $\mathrm{O}_{2}$ reduction reaction on the cathode. Similarly, the excellent electrochemical performance of the ORR certainly results in a peak potential close to the $\mathrm{Pt} / \mathrm{C}$, or even surpassing $\mathrm{Pt} / \mathrm{C}$ to a more positive potential. (3) The peak current density is another factor associated with peak potential to further explain the ORR activity. Corresponding to the peak potential, the obtained peak current density indicates the effectiveness 
of electron transport through the cathode. Therefore, the better ORR capacity of an electrode surely leads to an enormous peak current density, which benefits from the rapid transportation of electrons among oxygen, water and the cathode.

Linear sweep voltammetry analysis (LSV). LSV analysis is another crucial method that describes the ORR activity of synthesized nanocomposites using a rotating-disk electrode (RDE) or rotating ring-disk electrode (RRDE). ${ }^{4,111-113}$ Similar to $\mathrm{CV}$ measurements, the LSV analysis is also performed in an $\mathrm{O}_{2}$ saturated $0.1 \mathrm{M} \mathrm{KOH}$ solution at different rotation rates under room temperature. The electrolytic bath includes three electrodes: a RDE or RRDE quantitatively coated with the catalyst under investigation, an $\mathrm{Ag} \mid \mathrm{AgCl} / \mathrm{KCl}$ (saturated) reference electrode and a Pt wire as a counter electrode. When the working electrode is rotated steadily at the required rotation rate, the changes of current density can be attained in the potential range referred to the $\mathrm{CV}$ for one linear sweep. In particular, the working electrode of RDE or RRDE consists of a $5.61 \mathrm{~mm}$ diameter glassy carbon disk (RDE), or another Pt ring with an inner diameter of $6.25 \mathrm{~mm}$ and an outer diameter of $7.92 \mathrm{~mm}$ (RRDE).

Fig. 14 shows series of LSV analysis of different synthesized nanocatalysts for ORR activity. In Fig. 14a, a standard LSV of commercial Pt/C NPs with its onset and half-wave potential nearly -0.04 and $-0.137 \mathrm{~V}$, respectively, can be observed, and the peak current density is $\sim 5.4 \mathrm{~mA} \mathrm{~cm}{ }^{-2}$. In contrast, the $\mathrm{MnFe}_{2} \mathrm{O}_{4}$ NPs had better ORR activity due to the half-wave potential at $-0.154 \mathrm{~V}$, and a more positive onset potential at $0 \mathrm{~V} \cdot{ }^{114}$ Sun and coworkers ${ }^{109}$ compared the ORR activity of
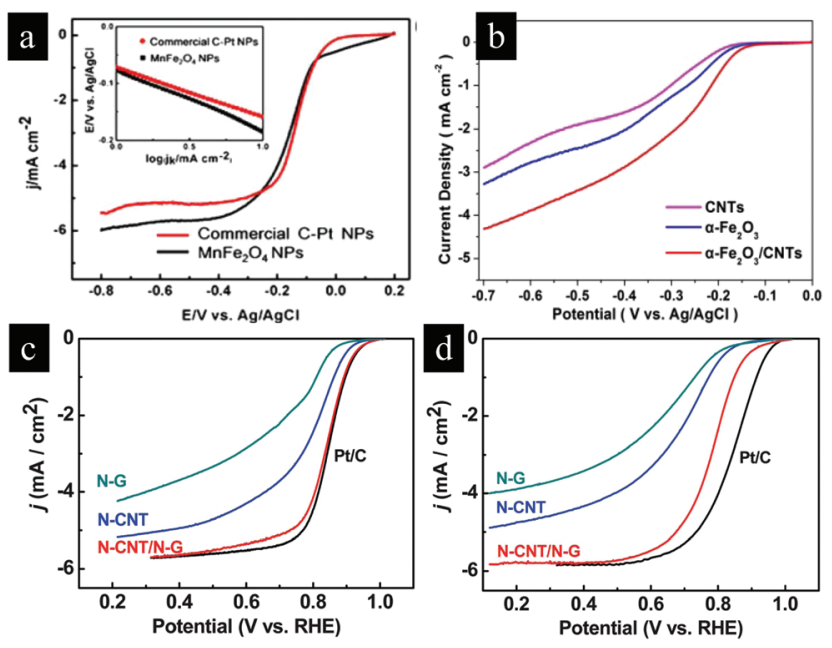

Fig. 14 (a) LSVs for $\mathrm{MnFe}_{2} \mathrm{O}_{4} \mathrm{NPs}$ and commercial C-Pt NPs at 1600 rpm in $\mathrm{O}_{2}$-saturated $0.1 \mathrm{M} \mathrm{KOH}$ at a scan rate of $10 \mathrm{mV} \mathrm{s}^{-1}$. (b) LSV curves of CNTs, $\alpha-\mathrm{Fe}_{2} \mathrm{O}_{3}$ and $\alpha-\mathrm{Fe}_{2} \mathrm{O}_{3} / \mathrm{CNTS}$ nanocomposites in $\mathrm{O}_{2}$ saturated $0.1 \mathrm{M} \mathrm{KOH}$ solution at a rotation rate of $1600 \mathrm{rpm}$. Sweep rate: $5 \mathrm{mV} \mathrm{s}^{-1}$. (c) ORR polarization curves measured at the scanning rate of $5 \mathrm{mV} \mathrm{s}^{-1}$ and an electrode rotation rate of $1600 \mathrm{rpm}$ in $\mathrm{O}_{2}$-saturated 0.1 $\mathrm{M} \mathrm{KOH}$ solution, and (d) in $\mathrm{O}_{2}$-saturated $0.1 \mathrm{M} \mathrm{HClO} 4$ solution. Reproduced with permission from ref. 114. Copyright ACS 2014; from ref. 109. Copyright ACS 2013; from ref. 115. Copyright ACS 2012. carbon nanotubes (CNTs), $\alpha-\mathrm{Fe}_{2} \mathrm{O}_{3}$ nanoparticles, and $\alpha-\mathrm{Fe}_{2} \mathrm{O}_{3} /$ CNTs nanocomposites in an $\mathrm{O}_{2}$-saturated $0.1 \mathrm{M} \mathrm{KOH}$ solution at a rotation rate of $1600 \mathrm{rpm}$. Evidently, the onset potential, half-wave potential, and the peak current density of the three nanocatalysts increased in the sequence CNTs $<\alpha-\mathrm{Fe}_{2} \mathrm{O}_{3}<$ $\alpha-\mathrm{Fe}_{2} \mathrm{O}_{3} / \mathrm{CNTs}$, indicating that the $\alpha-\mathrm{Fe}_{2} \mathrm{O}_{3} / \mathrm{CNTs}$ had the best ORR electrocatalytic activity compared to the other catalysts. As seen from Fig. $14 \mathrm{c}$ and $\mathrm{d}$, the polarization curves of the ORR were measured in $\mathrm{O}_{2}$-saturated $0.1 \mathrm{M} \mathrm{KOH}$ and $\mathrm{HClO}_{4}$ solutions, respectively. ${ }^{115}$ The nanocomposite of N-CNTs/N-G exhibited considerably higher ORR activities than N-G and $\mathrm{N}-\mathrm{CNT}$ and also displayed slight differences in alkaline and acidic solutions compared with $\mathrm{Pt} / \mathrm{C}$. In alkaline solution, the LSV of N-CNTs/N-G was the same as that of Pt/C. However, there was about $60 \mathrm{mV}$ gap of the half-wave potential of N-CNTs/N-G, approaching to that of Pt/C. Particularly, we found that large BET surface of N-CNTs/N-G $\left(134 \mathrm{~m}^{2} \mathrm{~g}^{-1}\right)$, about two times bigger than that of the N-CNT $\left(68 \mathrm{~m}^{2} \mathrm{~g}^{-1}\right)$, may contribute to its super ORR currents by a value considerably larger in magnitude than two fold, particularly in acidic solution.

Actually, the LSV analysis not only plays a vital role in evaluating the ORR activity of catalysts, but also provides foundations to get further insights into ORR performance. For example, the electron transfer number $(n)$ involved in an oxygen reduction processed by $\mathrm{RDE}$ can be indirectly calculated on the basis of the Koutecky-Levich (K-L) equations shown below [eqn (1)-(3)]: ${ }^{116-118}$

$$
\begin{gathered}
\frac{1}{J}=\frac{1}{J_{\mathrm{K}}}+\frac{1}{J_{\mathrm{L}}}=\frac{1}{B \omega^{\frac{1}{2}}}+\frac{1}{J_{\mathrm{K}}} \\
B=0.62 n F C_{0} D_{0}{ }^{\frac{2}{3}} v^{-\frac{1}{6}} \\
J_{\mathrm{K}}=n F k C_{0}
\end{gathered}
$$

where $J$ is the measured current density, which can be obtained directly from the LSV polarization curve; $\omega$ is the electrode rotating rate, and can be calculated by $\omega=2 \pi N(N$ is the linear rotation speed); $F$ is the Faraday constant (96485 C $\left.\mathrm{mol}^{-1}\right) ; C_{0}$ is the bulk concentration of $\mathrm{O}_{2}\left(1.1 \times 10^{-6} \mathrm{~mol}\right.$ $\left.\mathrm{cm}^{-3}\right), D_{0}$ is the diffusion coefficient of $\mathrm{O}_{2}$ in the $\mathrm{KOH}$ electrolyte $\left(1.9 \times 10^{-5} \mathrm{~cm}^{2} \mathrm{~s}^{-1}\right), v$ is the kinematic viscosity of the electrolyte $\left(1.0 \times 10^{-2} \mathrm{~cm}^{2} \mathrm{~s}^{-1}\right.$ in $\left.0.1 \mathrm{M} \mathrm{KOH}\right)$, and $k$ is the electron transfer rate constant. $J_{\mathrm{K}}$ and $J_{\mathrm{L}}$ are the kinetic and diffusion limiting current densities. $n$ is the number of electrons transferred in the ORR, which can be finally calculated by the corresponding $\mathrm{K}-\mathrm{L}$ plots with good linearity. In particular, a series of $\mathrm{K}-\mathrm{L}$ plots with perfect parallelism obtained by different rotation speeds suggest a similar electron-transfer number per $\mathrm{O}_{2}$ molecule involved and first-order dependence of $\mathrm{O}_{2}$ kinetics in the ORR. ${ }^{119}$ According to eqn (1) and (2), n can be calculated at corresponding potentials derived from the polarization curve. Generally, $n$ increases as potential increases; therefore, the appropriate range of potentials is crucial for the scientific calculation of $n$ value. For instance, according to Fig. 14b, $n$ was calculated to be 3.05 at $-0.60 \mathrm{~V}$ 
for CNTs, 3.12 at $-0.60 \mathrm{~V}$ for $\alpha-\mathrm{Fe}_{2} \mathrm{O}_{3}$ and 3.45 at $-0.60 \mathrm{~V}$ for $\alpha-\mathrm{Fe}_{2} \mathrm{O}_{3} / \mathrm{CNTs}$. This result indicated the oxygen reductions on CNTs and $\alpha-\mathrm{Fe}_{2} \mathrm{O}_{3}$ both processed in a two- and four-electron pathways, but the $\alpha-\mathrm{Fe}_{2} \mathrm{O}_{3} / \mathrm{CNTs}$ had a higher four-electron pathway. Moreover, based on the eqn (3), the calculated $J_{\mathrm{K}}$ for CNTs, $\alpha-\mathrm{Fe}_{2} \mathrm{O}_{3}$ and $\alpha-\mathrm{Fe}_{2} \mathrm{O}_{3} / \mathrm{CNTs}$ were $6.19,7.39$ and $18.48 \mathrm{~mA}$ $\mathrm{cm}^{-2}$ at $-0.60 \mathrm{~V}$, respectively, indicating the notable ORR activity of $\alpha-\mathrm{Fe}_{2} \mathrm{O}_{3} / \mathrm{CNTS}$ catalyst. Sometimes, LSV curves at various rotation rates were investigated to calculate the average electron transfer number to completely understand the ORR process on cathodes. As can be seen in Fig. 15a, the polarization curves of the ORR on synthesized PDDA-graphene electrodes were analyzed at rotation rates from 200 to $1400 \mathrm{rpm}$. The resulting K-L plots show a parallel correlation (Fig. 15b). The calculated $n$ and $J_{\mathrm{K}}$ values of PDDA-graphene electrodes both decreased at the potential range from -1.2 to $-0.6 \mathrm{~V}$, but was still markedly higher than graphene.

As mentioned above, more information of an ORR performance can be indirectly attained by $\mathrm{K}-\mathrm{L}$ plots derived from the LSV analysis using a RDE cathode. In fact, the electron transfer number involved in oxygen reduction can be calculated more simply and expediently by a RRDE cathode. A Pt ring cathode with an inner diameter of $6.25 \mathrm{~mm}$ and an outer diameter of $7.92 \mathrm{~mm}$ is used to monitor the formation of the intermediates peroxide species $\left(\mathrm{HO}_{2}{ }^{-}\right)$during the ORR. The percentage of $\mathrm{HO}_{2}{ }^{-}$and the electron transfer number can be determined by the following equations.

$$
\begin{gathered}
\mathrm{HO}_{2}{ }^{-} \%=200 \times \frac{i_{\mathrm{R}} / N}{i_{\mathrm{D}}+i_{\mathrm{R}} / N} \\
n=4 \times \frac{i_{\mathrm{D}}}{i_{\mathrm{D}}+i_{\mathrm{R}} / N}
\end{gathered}
$$
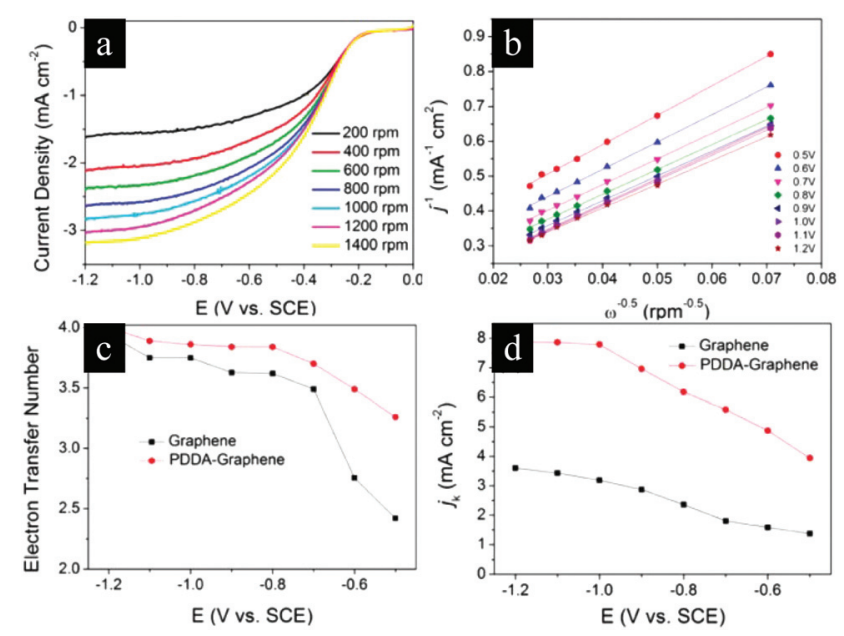

Fig. 15 (a) LSV curves at different rotation rates for oxygen reduction at a PDDA-graphene electrode in an $\mathrm{O}_{2}$-saturated $0.1 \mathrm{M} \mathrm{KOH}$ solution. (b) $\mathrm{K}-\mathrm{L}$ plots of ORR on PDDA-graphene electrode. (c) The dependence of the electron transfer number and (d) the kinetic current density on the potential for both the graphene and PDDA-graphene electrodes. Reproduced with permission from ref. 91. Copyright ACS 2011. where $i_{\mathrm{D}}$ and $i_{\mathrm{R}}$ are the disk and the ring currents, respectively. $\mathrm{N}$ represents the current collection efficiency of the Pt ring, which is confirmed to be 0.36 by reducing $\mathrm{K}_{3} \mathrm{Fe}[\mathrm{CN}]_{6}$, which is consistent with the manufacturer's value (0.37). ${ }^{15} \mathrm{RRDE}$ measurements of GO, CuO/GO, N-rGO, CuO/N-rGO, and Pt/C in an $\mathrm{O}_{2}$-saturated $0.1 \mathrm{M} \mathrm{KOH}$ solution at $1600 \mathrm{rpm}$ with scan rate $5 \mathrm{mV} \mathrm{s}^{-1}$ are shown in Fig. 16a. ${ }^{73} \mathrm{CuO} / \mathrm{GO}$ showed a higher ORR current density than GO, but also gave a higher ring current density, suggesting an identical reaction mechanism/pathway of the two catalysts. As a result, $\mathrm{CuO} / \mathrm{GO}$ showed a similar value of peroxide percentage (Fig. 16b) to those of GO. As for $\mathrm{CuO} / \mathrm{N}-\mathrm{rGO}$, the introduction of $\mathrm{CuO}$ not only elevated the disk current but also promoted the onset potential within $35 \mathrm{mV}$. Moreover, the ring current of $\mathrm{CuO} / \mathrm{N}-\mathrm{rGO}$ was considerably lower than that of N-rGO at the potential range from -0.8 to $-0.2 \mathrm{~V}$, resulting in a considerably lower peroxide percentage (mean value less than 20\%). The release of the stable intermediate peroxide lowers the efficiency of oxygen reduction and thus should be depressed as severely as possible. The Pt ring cathode recorded the current generated by the peroxide electrochemical oxidation. Therefore, a high ring current indicates a large amount of intermediate peroxide dominated in ORR, which indicated an undesirable kinetic process during ORR.

Electrochemical impedance spectroscopy (EIS). Electrochemical impedance spectroscopy (EIS) has tremendously increased its popularity in recent decades from the determination of double-layer capacitance to the characterization of electrode processes and complex interfaces. EIS reflects the electrochemical system response to the stimulation of an imposed periodic small amplitude ac signal. These measurements are carried out at different ac frequencies, and thereafter, the impedance spectroscopy can be consisted of the changes of the ratio between the ac potential and current signal with the corresponding sinusoid frequencies $(\omega)$. In oxygen reduction reaction, EIS analysis is conducive to reveal the kinetic process of the ORR containing some crucial information, including the interface and structure of the ORR electrode materials, effects of electric double layer and diffusion of $\mathrm{O}_{2}$, and mechanism of corrosion prevention. For example, the ORR kinetic electron transfer process commonly leads to an EIS plot with a semicircle and a linear portion corresponding

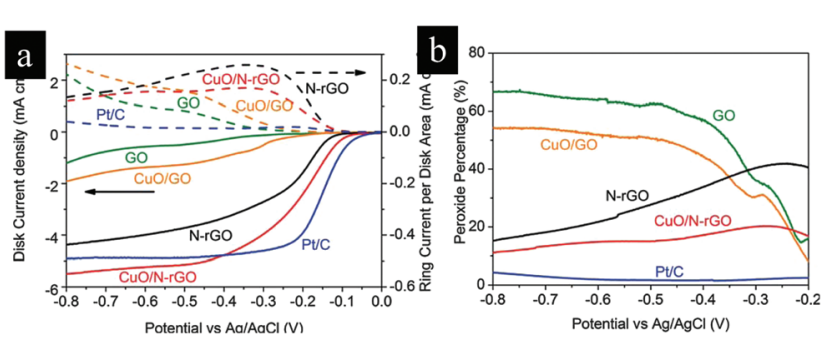

Fig. 16 (a) RRDE disk and ring current density with a rotation rate of $1600 \mathrm{rpm}$ in $0.1 \mathrm{M} \mathrm{KOH}$. Scan rate: $5 \mathrm{mV} \mathrm{s}^{-1}$ ). (b) Peroxide percentage of the catalysts vs. potential. Reproduced with permission from ref. 73. Copyright RSC 2013. 
to a charge transfer and mass transfer process at the high frequency and the low frequency range, respectively.

Oleg and coworkers ${ }^{120}$ probed the stable electrocatalytic activity towards $\mathrm{O}_{2}$ reduction on a deactivated $\mathrm{Au}$ electrode by EIS measurements. The typical EIS plots in the ORR kinetic process were systemically investigated. As shown in Fig. 17, the Nyquist plots were marked at different potentials. Fig. 17a illustrates a simple one arc impedance spectrum in the highpotential region; it corresponds with the reduction reaction from $\mathrm{O}_{2}$ to $\mathrm{HO}_{2}{ }^{-121,122}$ According to the data fitting to derive respective circuits at different potentials, the resistance of charge transfer $\left(R_{\mathrm{ct}}\right)$ grew during the electrode polarization and stopped in $\sim 6 \mathrm{~h}$. With the increase of electrode polarization, more inductive factors and various structures appeared in the spectral structure (Fig. 17b-d). Diffusion short-circuit Warburg impedance $\left(W_{\mathrm{s}}\right)$ emerged at potentials lower than $-0.28 \mathrm{~V}$. $W_{\mathrm{s}}$ involves the parameter $\left(T_{\mathrm{w}}\right)$ that can be used to calculate the diffusion coefficient. Eqn (6) clearly demonstrates the capacitive feature of $W_{\mathrm{s}}$. The impedance spectrum with a "capacitive-like" arc of $W_{\mathrm{s}}$ was well fitted in Fig. 17b. In eqn (7), $l$ is the effective double layer thickness, $v$ is the kinematic viscosity, $w$ is the rotating rate $\left(\operatorname{rad~s}^{-1}\right)$, and $D$ is the diffusion coefficient. Thus, $T_{\mathrm{w}}$ can be evaluated for different conditions, which is inversely proportional to the rotation rate of disk electrode.

$$
\begin{gathered}
Z_{W_{\mathrm{s}}}=\frac{R_{\mathrm{d} \cdot} \cdot \tan h\left(\left[j \omega T_{\mathrm{w}}\right]^{0.5}\right)}{\left[j \omega T_{\mathrm{w}}\right]^{0.5}} \\
T_{\mathrm{w}}=\frac{l^{2}}{D} \cdot \frac{2.59 \cdot v^{1 / 3}}{D^{1 / 3}} \cdot \frac{1}{w}
\end{gathered}
$$

The adsorptive impedance caused by the adsorption of long life intermediate species in the ORR on the electrode surface is
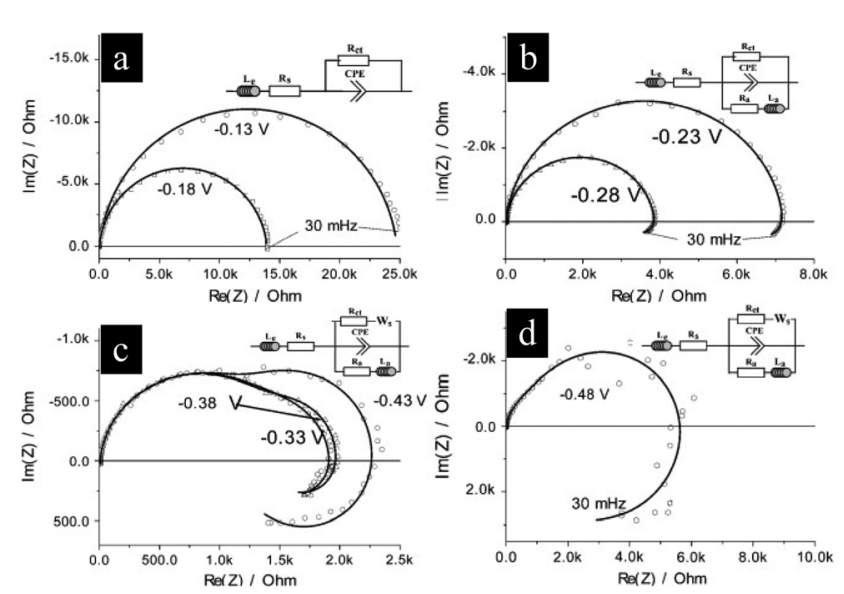

Fig. 17 Nyquist plots of electrochemical impedance and respective equivalent circuits of the ORR on deactivated $p$-Au electrode at different electrode potentials (vs. NHE). Points - experimental data, lines - fitting using the equivalent circuits. $L_{e}$ - inductivity of conductive system, $L_{a}-$ adsorptive inductivity, $R_{\mathrm{s}}$ - solution resistance, $R_{\mathrm{ct}}$ - resistance of charge transfer, $R_{\mathrm{a}}$ - adsorptive resistance, $W_{\mathrm{s}}-$ Warburg short-circuit impedance, CPE - constant phase element. Conditions: $1 \mathrm{M} \mathrm{NaOH}$, $1500 \mathrm{rpm}, \mathrm{O}_{2}$. Reproduced with permission from ref. 120. Copyright Elsevier 2014. connected with the inductive element, and also led to some typical impedance spectrum (Fig. 17c and d). The impedance spectrum behaves in different shapes of semicircles with a respective diameter, suggesting the main process of the intermediate transformation at different potential regions. For instance, the smaller diameter of the semicircle for graphene based nanocomposites compared to supporting transition metal oxides and graphene indicated that the nanocomposites significantly enhanced the electron transfer, which also could promote the catalytic ORR considerably easier and more efficiently than metal oxides without graphene supports. ${ }^{51,64}$ Similarly, the EIS plots with a straight line in the low-frequency region and a small arc in the high frequency region regarding their high electronic resistance implied that the high conductivity of rGO nanosheets can enhance charge transportation. ${ }^{94}$

Other electrocatalytic ORR characterization. Current-time $(I-t)$ chronoamperometric responses exhibit concise and visual polarization curves for methanol tolerance and durability measurement of synthesized catalysts. These crossover effects can be assessed by adding methanol into an $\mathrm{O}_{2}$-saturated $0.1 \mathrm{M} \mathrm{KOH}$ solution. The durability of the nanocomposites compared with a Pt/C catalyst for the ORR can be evaluated by chronoamperometry at $-0.3 \mathrm{~V}$ in $\mathrm{O}_{2}$-saturated $0.1 \mathrm{M} \mathrm{KOH}$ solutions. In general, a steady polarization curve without a marked decline demonstrates that the catalysts have promise for direct methanol fuel cell applications. We will discuss the characterization of current-time chronoamperometric responses elaborately in the following sections.

\section{Applications of graphene- supported transition metal oxides nanocomposites in ORR}

With the increasing global energy crises, renewable and sustainable new energy resources have been paid close attention due to their promising high energy density and rare environmental damage compared to traditional fossil energy. In the electrochemical cell, the oxygen reduction reaction on cathode is the fundamental reaction, and it notably determines the efficiency of a fuel cell. As mentioned above, the four-electron-transfer pathway with the formation of $\mathrm{H}_{2} \mathrm{O}$ as the end product is the desirable ORR process. However the undesirable two-electrontransfer reduction of $\mathrm{O}_{2}$ to $\mathrm{HO}_{2}{ }^{-}$has become the key factor limiting its performance of ORR. Recently, the intensive studies on graphene based nanocatalysts with the delightful activity of the kinetics of ORR have made great progress. However, the further requirements of durable and preservative electrode materials in overcoming crossover effects and $\mathrm{CO}$ poisoning are urgent. In this section, we will discuss the applications of graphenesupported transition metal oxide nanocatalysts in ORR.

\subsection{Potentials direct methanol fuel cells (DMFCs)}

DMFCs, just as its name indicates, utilizes methanol as a fuel candidate and has been considered as one of the most promis- 
ing fuels for the direct alcohol fuel cells due to the superiority of low molecular weight and structure, and large energy density. In DMFCs, the adsorption of methanol and the subsequent decomposition are dominant on the anode. However, the diffusion of methanol from the anode to the cathode is difficult to avoid, resulting in negative effects on the efficiency of ORR at the cathode. Moreover, the intermediate $\mathrm{CO}$ is another type of poisonous substance, which can markedly reduce the catalytic activity of commercial ORR cathodes. Therefore, there is a consensus that the promising cathodes in DMFCs should have some advantages such as high catalytic activity of ORR, long durability in methanol solution and resistant capacity of $\mathrm{CO}$ poisoning.

To investigate the electrocatalytic ORR activity of graphenesupported transition metal oxide nanocomposites in DMFCs, CVs and current $(I)$-time $(t)$ chronoamperometric responses are helpful to determine the methanol tolerance and durability of cathodes. The property of methanol tolerance in the ORR is often investigated in $\mathrm{O}_{2}$-saturated $0.1 \mathrm{M} \mathrm{KOH}$ solutions with $3 \mathrm{M}$ methanol. As shown in Fig. 18a, the CV curve of titanium nitride nanocrystals on a nitrogen-doped graphene (TiN/NG) cathode in $\mathrm{O}_{2}$-saturated $0.1 \mathrm{M} \mathrm{KOH}$ solutions with $3 \mathrm{M}$ methanol performed similar to that in $\mathrm{O}_{2}$-saturated $0.1 \mathrm{M} \mathrm{KOH}$ solutions, suggesting that the TiN/NG cathode had excellent methanol stability and promising applications in DMFCs. ${ }^{7}$

The current-time $(I-t)$ chronoamperometric response of the cathode has been widely used as an effective method to test the catalytic stability and crossover or poison effects in the ORR. ${ }^{123-125}$ For example, the catalytic stability of the TiN/NG and $\mathrm{Pt} / \mathrm{C}$ for ORR was investigated by chronoamperometry at $0.3 \mathrm{~V}$ in $\mathrm{O}_{2}$-saturated $0.1 \mathrm{M} \mathrm{KOH}$ solutions at a rotation rate of $1600 \mathrm{rpm}$ (Fig. 18b). The decline in current on the TiN/NG electrode was only $10 \%$ after it was cycled for $25000 \mathrm{~s}$, which was considerably less than that of $\mathrm{Pt} / \mathrm{C}(27 \%)$, indicating that the TiN/NG had better stability than commercial Pt/C catalysts. In addition, for the effects of crossover or CO poisoning on ORR, Yan and coworkers ${ }^{74}$ used the current-time chronoamperometric response to test the tolerance of the $\mathrm{Cu}_{2} \mathrm{O} / \mathrm{RGO}$ catalysts to methanol (Fig. 18c). There was nearly no significant decrease after the addition of methanol, demonstrating that the $\mathrm{Cu}_{2} \mathrm{O} / \mathrm{RGO}$ catalyst had notable methanol tolerance in the ORR. In addition, the effect of $\mathrm{CO}$ poisoning on the $\mathrm{Cu}_{2} \mathrm{O} /$ $\mathrm{RGO}$ electrode was also investigated in the presence of $\mathrm{CO}$ in $\mathrm{O}_{2}$-saturated $0.1 \mathrm{M} \mathrm{KOH}$. Fig. $18 \mathrm{~d}$ shows the $I-t$ chronoamperometric responses of the $\mathrm{Cu}_{2} \mathrm{O} / \mathrm{RGO}$ electrode in $\mathrm{O}_{2}$ and $\mathrm{O}_{2}+$ $\mathrm{CO}$ saturated $\mathrm{KOH}$. When $\mathrm{CO}$ was added, only a slight and slow decrease in the electrocatalytic activity of the $\mathrm{Cu}_{2} \mathrm{O} / \mathrm{RGO}$ electrode could be observed $(\sim 20 \%)$, indicating that $\mathrm{Cu}_{2} \mathrm{O} /$ RGO exhibited better CO resistance than that of the $\mathrm{Pt} / \mathrm{C}$ catalyst.

In DMFC, the diffusion of methanol molecules from the anode to the cathode through the polymer electrolyte membrane, always causes severe deactivation of the ORR on the cathode. The CO poisoning on a noble metal cathode to decrease the catalytic ORR activity also cannot be ignored. Therefore, a good DMFC cathode should be able to selectively
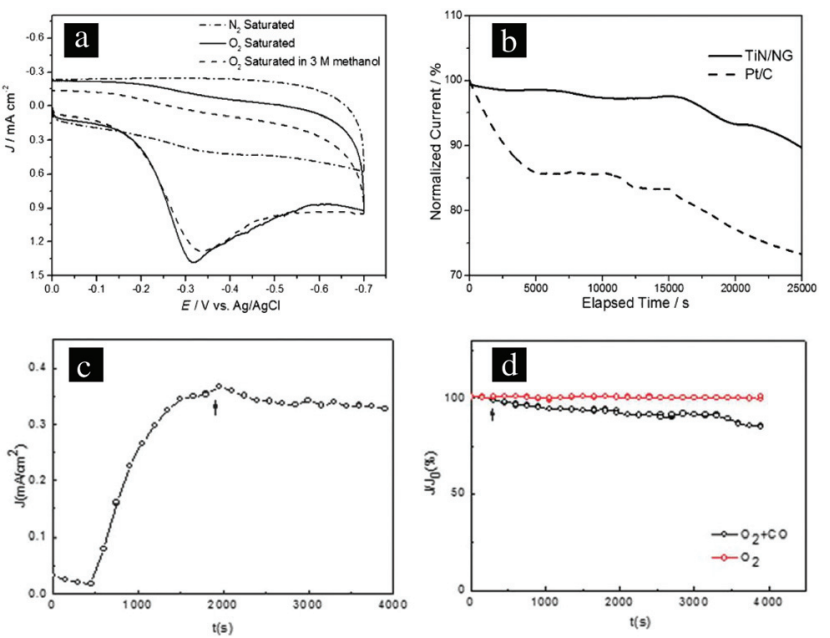

Fig. 18 (a) Cyclic voltammograms of TiN/NG in $\mathrm{N}_{2}$ and $\mathrm{O}_{2}$-saturated $0.1 \mathrm{M} \mathrm{KOH}$ solutions as well as $\mathrm{O}_{2}$-saturated $0.1 \mathrm{M} \mathrm{KOH}$ solution with 3 $M$ methanol. Scan rate: $50 \mathrm{mV} \mathrm{s}^{-1}$. (b) Current-time $(I-t)$ responses of TiN/NG and $\mathrm{Pt} / \mathrm{C}$ at $-0.30 \mathrm{~V}$ in $\mathrm{O}_{2}$-saturated $0.1 \mathrm{M} \mathrm{KOH}$ solutions. The rotation rate is $1600 \mathrm{rpm}$. (c) Current-time $(I-t)$ chronoamperometric response of $\mathrm{Cu}_{2} \mathrm{O} / \mathrm{RGO}$ electrode at $-0.4 \mathrm{~V}$ in $\mathrm{O}_{2}$-saturated $0.1 \mathrm{M} \mathrm{KOH}$ solution. The arrow indicates the addition of $2 \%(\mathrm{w} / \mathrm{w})$ methanol. (d) Current-time $(I-t)$ chronoamperometric response of $\mathrm{Cu}_{2} \mathrm{O} / \mathrm{RGO}$ electrode at $-0.4 \mathrm{~V}$ in an $\mathrm{O}_{2}$-saturated $0.1 \mathrm{M} \mathrm{KOH}$ solution. The arrow indicates the addition of $10 \%(\mathrm{v} / \mathrm{v}) \mathrm{CO}$ into $\mathrm{O}_{2}$-saturated $0.1 \mathrm{M} \mathrm{KOH}$ at -0.4 $V_{i} j_{0}$ defines the initial current. Reproduced with permission from ref. 7. Copyright Wiley 2013; and ref. 8. Copyright Wiley 2013; and ref. 74. Copyright RSC 2012.

reduce oxygen, instead of oxidizing methanol. As mentioned above, the graphene based transition metal oxide nanocatalysts not only had highly efficient ORR activity, but also exhibited excellent methanol tolerance and long durability, leading to promising applications in DMFCs.

\subsection{Other fuel cells}

Similar with DMFCs, a variety of fuel cells containing different anode reactions, such as the hydrogen oxidation reaction (HOR), ethanol oxidation reaction (EOR) and formic acid oxidation reaction (FAOR), were named hydrogen-fed fuel cells, direct alcohol fuel cells, and direct formic acid fuel cells, respectively. These fuel cells are strictly required for the high efficiency of ORR at the cathode to achieve a promising power density. Other important properties of the cathode, including long-term durability and corrosion-tolerance, are also strongly demanded. In long term electrocatalysis, the agglomeration of commercial $\mathrm{Pt} / \mathrm{C}$ and the electrochemical corrosion of supports in strongly acidic/alkaline environments led to the deactivation of the catalysts. ${ }^{13}$ Moreover, the negative electronic effects results in the shift of the Pt d-band center, and thereafter weakens the bond strength of the adsorbed intermediate $\mathrm{CO}$, and decreases the effectiveness of the ORR at the cathode ${ }^{126}$ Therefore, developing durable and tolerable ORR catalysts in optimizing the electrocatalytic cathodic process is necessary. As mentioned above, on one hand, the graphene based transition metal oxide cathodes displayed a desirable 
catalytic performance of ORR due to the high surface area, excellent conductivity, and special crystal nanostructure of the nanocomposites. On the other hand, the durability and tolerance of graphene based nanocomposites are notably improved, and these graphene based cathodes also exhibited great potential in solving the problems of crossover and CO poisoning during the ORR process in different fuel cells.

$\mathrm{Co}_{3} \mathrm{O}_{4} /$ graphene, ${ }^{55} \quad \mathrm{MnCo}_{2} \mathrm{O}_{4} / \mathrm{N}-\mathrm{rGO},{ }^{56} \quad \mathrm{FeO}_{x} /$ graphene ${ }^{15,41,43,45,48} \mathrm{CuO} / \mathrm{N}-\mathrm{rGO},{ }^{74}$ and $\mathrm{TiO}_{2}-\mathrm{FGSs}^{77}$ nanocomposites were proven to have comparable ORR activity, long catalytic stability, and better tolerance to methanol crossover and $\mathrm{CO}$ poisoning compared with commercial Pt/C. The strong and intimate electrical and chemical couplings between transition metal oxide nanoparticles and graphene can promote the charge transfer between interfaces and molecules. Furthermore, the high intrinsic structural stability of graphene and the strong interactions among the modified transition metal oxides can largely improve its stability and durability under harsh electrocatalytic conditions. The appropriate content of modified transition metal oxides supported on graphene makes the nanocomposites prefer to adsorb $\mathrm{O}_{2}$ molecules on the surface and leads to the rapid diffusion of electrons and sufficient contact between $\mathrm{O}_{2}$ and active sites on the surface.

\subsection{Oxygen reduction reaction at the cathode}

As mentioned above, oxygen reduction reaction at the cathode plays a crucial role in determining the performance of a fuel cell. Various catalytic cathode materials with a direct four-electron oxygen reduction pathway, low onset and half-wave potential, high peak current density have been intensively studied. ${ }^{40,45,127-129}$ Although the commercialized Pt and Pt alloys have a number of challenges, including high cost and easy poisoning from methanol crossover, they still possess better ORR properties than the majority of cathode materials in onset and half-wave potential..$^{2-4,130}$ In recent decades, studies on the electrocatalysts of low-Pt or non-noble metal supported on graphene with low-cost, high electrocatalytic activity, and ORR stability have achieved substantial progress. In particular, the graphene-based transition metal oxide nanocomposites show outstanding ORR performance in saving cost, thus further decreasing the onset and half-wave potentials, elevating the durability and methanol tolerance. ${ }^{43,47,48,50-52,55,59,65,66,68,69,74,114,131,132}$

Iron containing nanoparticles on graphene catalysts have been found to be a group of promising non-noble metal nanocatalysts for the ORR. In a recent work, ${ }^{43}$ three-dimensional $\mathrm{N}$-doped graphene aerogel-supported $\mathrm{Fe}_{3} \mathrm{O}_{4}$ nanoparticles $\left(\mathrm{Fe}_{3} \mathrm{O}_{4} / \mathrm{N}-\mathrm{GAs}\right)$ were synthesized for the efficient catalysis of the ORR. The nanocomposites exhibited a more positive onset potential of $-0.19 \mathrm{~V}$, higher peak current density of $-2.56 \mathrm{~mA}$ $\mathrm{cm}^{-2}$, lower $\mathrm{H}_{2} \mathrm{O}_{2}$ yield of $11 \%$ at $-0.4 \mathrm{~V}$, and higher electron transfer number (3.95) for the ORR in alkaline media. $\mathrm{FeO}_{x}$ / GNs synthesized by the monovalent functionalization of GNs with iron precursors, such as the iron phthalocyanine/tetrasulfophthalocyanine/polyphthalocyanine (FePc/FeTsPc/FePPc), attracted considerable attention due to their better catalytic performance for the ORR. ${ }^{15,40,41,44,45}$ The synthesized strategy showed a promising way to prevent the aggregation of GNs, because the anchoring of an iron complex/polymer between the adjacent graphene layers decreased the interactions of the carbon framework. For instance, Cui and coworkers ${ }^{45}$ found that the peak potential of the ORR on $\mathrm{FeO}_{x}$ /graphene (using FePc as precursors) nanocatalysts reached around -0.195 in a $0.1 \mathrm{M} \mathrm{NaOH}$ solution, which was more positive than Pt/C. Gao et $a l .{ }^{44}$ utilized the ascendant properties of GNs and FeTSPc, and the resulting iron oxides/graphene nanocomposites outperformed commercial $\mathrm{Pt} / \mathrm{C}$ due to the high cathodic current density of $0.86 \mathrm{~mA} \mathrm{~cm} \mathrm{~cm}^{-2}$ at $-0.10 \mathrm{~V}$, indicating its reduced overpotential and enhanced current response. The kinetic process of the ORR for this electrode was proven to follow a nearly four-electron pathway. It was found that the mechanism of the ORR of this class of nanocomposites can be ascribed to the active redox property of the different valencies of $\mathrm{Fe}^{40,41} \mathrm{~A}$ novel iron oxyhydroxide nanocomposite of $\mathrm{FeOOH}$ nanoparticles well-dispersed on reduced graphene oxide (FeOOH/rGO) were produced by a one-pot solution process. ${ }^{133}$ The catalysts exhibited good catalytic performance for the ORR in attaining an onset potential of $0.76 \mathrm{~V}$ ( $v s$. the reversible hydrogen electrode, RHE), a near four electron pathway, and excellent stability against methanol poisoning. Xia and coworkers summarized the one-pot synthesis method of nanocatalysts of nitrogen-doped graphene decorated with $\mathrm{M}(\mathrm{OH})_{x}(\mathrm{M}=\mathrm{FeO}, \mathrm{Ni}$, Co) nanoparticles, which possessed excellent electrochemical properties. It was found that the urea, used in the synthetic process, played a prominent role in not only acting as the reducing agent and doping agent for nitrogen-doped graphene, but also providing hydroxyls for the combination of metal hydroxides and oxide-hydroxide. ${ }^{134}$ Actually, cobalt has similar chemical properties compared to iron; thus, cobalt oxide supported graphene showed comparable electrocatalytic activity of the ORR. ${ }^{51,55,56,59,135}$ As mentioned above, Wu et al. ${ }^{135}$ prepared $\mathrm{Co}(\mathrm{OH})_{2}$ /graphene nanocomposites with a larger peak current towards the ORR at a low onset potential of -0.19 V. Furthermore, Jeon and coworkers ${ }^{136}$ used cobalt-porphyrin (COAPFP) as a precursor to functionalize GO. RDE and RRDE measurements indicated that an approximate four-electron $(n>3.8)$ ORR process commenced at -0.3 to $-0.7 \mathrm{~V}$, and the percentage of generated hydrogen peroxide could be attained less than $15 \%$. The obtained nanocomposites of $\mathrm{Co}_{3} \mathrm{O}_{4} /$ graphene ${ }^{55}$ and $\mathrm{Co}_{3} \mathrm{O}_{4} / \mathrm{rGO}^{51}$ both favored the efficient four electron oxygen reduction process. Recently, $\mathrm{Co} / \mathrm{CoO} /$ graphene catalysts with elaborate assembly of $\mathrm{CoO} / \mathrm{GNs}$ hybrids, formed on the surface of Co (Co-CoO/GNs), were successfully synthesized. ${ }^{59}$ In addition to monometallic Co nanoparticles, bimetallic materials of cobalt and other metals were also reported to promote the electrocatalytic efficiency of the ORR. Liang et al. ${ }^{56}$ developed non-noble $\mathrm{MnCo}_{2} \mathrm{O}_{4} /$ graphene electrocatalysts through direct nucleation and growth of nanoparticles on $\mathrm{N}$-doped reduced graphene oxides and cation substitution of $\mathrm{Co}_{3} \mathrm{O}_{4}$. As compared to the $\mathrm{Co}_{3} \mathrm{O}_{4} / \mathrm{N}-\mathrm{mGO}$ catalysts, the $\mathrm{MnCo}_{2} \mathrm{O}_{4} / \mathrm{N}-\mathrm{mGO}$ has higher catalytic activity with an onset potential and peak potential of 0.95 and $0.88 \mathrm{~V}$, respect- 
ively, vs. RHE. The unexpected yield of peroxide species calculated from RRDE analysis was less than $10 \%$ over the $\mathrm{MnCo}_{2} \mathrm{O}_{4} / \mathrm{N}$-mGO cathode, and the average electron transfer number was $\sim 3.9$ from 0.9 to $0.5 \mathrm{~V}$.

Manganese oxides have become another important member of the big non-noble metal nanocatalyst family. ${ }^{61,63,137,138}$ The variety of manganese valencies contributes to the diversity of manganese oxides such as, MnO, $\mathrm{MnO}_{2}$, and $\mathrm{Mn}_{3} \mathrm{O}_{4}$. It was found that graphene based manganese oxides exhibited comparable catalytic activity in the ORR process compared to other graphene based transition metal oxides. For example, $\mathrm{MnO}_{2} /$ graphene, ${ }^{68} \mathrm{MnO}_{2} / \mathrm{rGO},{ }^{66,94}$ and $\mathrm{MnO}_{2}$-coated carbon nanotubes on graphene $(\mathrm{Mn}-\mathrm{C} / \mathrm{rGO})^{139}$ were reported to have better electrocatalytic capacity for the ORR and long durability in alkaline solution than Pt/C. However, slight differences of ORR activity of the above catalysts depended strongly on the crystallographic structures with the order of $\alpha->\beta->\gamma-\mathrm{MnO}_{2} \cdot{ }^{63,140}$ In addition, Bag et al. ${ }^{65}$ produced nitrogen-doped reduced graphene oxide- $\mathrm{Mn}_{3} \mathrm{O}_{4}$ hybrids by the one-step in situ growth of $\mathrm{Mn}_{3} \mathrm{O}_{4}$ nanoparticles on $\mathrm{N}$ rGO. The synthesized catalysts had an onset potential of $-0.075 \mathrm{~V}$, excellent methanol tolerance and high durability. Particularly, the average electron transfer number of $\mathrm{Mn}_{3} \mathrm{O}_{4}$ / $\mathrm{N}$-rGO was calculated to 3.8 , and its corresponding percentage of $\mathrm{HO}_{2}{ }^{-}$during ORR varies between $5 \%$ and $12.3 \%$ at -0.2 to $-0.6 \mathrm{~V}$, suggesting that the catalysts mainly favored the direct reduction of oxygen to water and had promising applications in fuel cells. Moreover, $\mathrm{Zhu}$ and coworkers $^{114}$ raised the concern of the synthesis of $\mathrm{M}_{x} \mathrm{Fe}_{3-x} \mathrm{O}_{4}(\mathrm{M}=\mathrm{Mn}, \mathrm{Fe}, \mathrm{Co}, \mathrm{Cu})$ nanocatalysts as super electrocatalysts for the ORR. They found that electrocatalytic activity decreased in sequence: $\mathrm{Mn}_{x} \mathrm{Fe}_{3-x} \mathrm{O}_{4}>\mathrm{Co}_{x} \mathrm{Fe}_{3-x} \mathrm{O}_{4}>\mathrm{Cu}_{x} \mathrm{Fe}_{3-x} \mathrm{O}_{4}>\mathrm{Fe}_{3} \mathrm{O}_{4}$, indicating the great potential for the ORR based on bimetallic graphene nanocomposites.

\section{Conclusions and perspectives}

There is no doubt that the discovery of graphene among the large carbon material family opens a new period of the development of many scientific fields such as material synthesis, electric, biotechnology, water treatment and medicine. In particular, the flourish of graphene based catalysts for energy conversion and storage greatly benefits from its unique structure and novel chemical and physical properties such as huge surface area, ultrahigh electrical conductivity, excellent mechanical properties, and super chemical stability. Moreover, cocatalysts transition metal oxides can be immobilized on graphene by intermolecular interactions of the defects and functional groups present on graphene's surface, contributing to the improved stability and catalytic activity of graphene-based transition metal oxide nanocomposite catalysts. This class of fabricated graphene-based transition metal oxide nanocatalysts exhibit super electrocatalytic activity for the ORR, which renders it an ideal electrocatalytic cathode for fuel cells.
In this feature article, we endeavor to review the recent development of graphene-based transition metal oxide nanocomposite cathodes for the ORR, including their synthesis, structures, characterizations, properties, and applications in fuel cells. In summary, the elaborate control in the morphology and dimension of the graphene based nanocomposite is essential because the electrochemical properties of ORR have been proven to be highly dependent on the morphology, size, defect, composition and construction in nanocomposites. Therefore, we firstly classified the graphene based catalysts by different transition metals, and their morphology and dimensional structure were simultaneously demonstrated. The characterization of nanocomposites and their electrocatalytic properties were intensively introduced, subsequently. Finally, the potential utilization of graphene-based transition metal oxide nanocomposite cathodes for the ORR in fuel cells was reviewed. The main results can be concluded as follows. (1) Multidimensional and multivalent transition metal oxides with special structures exhibited more attractive properties of the ORR than rough and nonstructural nanocomposites under similar experimental conditions. (2) XRD and XPS provided detailed information of the typical crystalline structure and composition of metal oxides. Raman and FTIR spectroscopy assisted to determine the molecular vibrations of functional groups. SEM, TEM and AFM showed irreplaceable capacities in directly acquiring structural and crystal images of composites in the nanoscale. (3) Electrocatalytic performance of the ORR based on graphene based transition metal should be characterized by CVs, LSV, RDE and RRDE measurements. The prominent parameters, including onset and half-wave potentials, peak currents and the calculated electron transfer numbers derived from K-L plots, were crucial for the sufficient identification of ORR property. EIS has the superiority of the determination of double-layer capacitance for the characterization of electrode processes and complex interfaces. (4) Promising applications of graphene based transition metal oxide nanocomposites in fuel cells largely depend on their desirable electrocatalytic stability and durability. The flexibility and immobilization of graphene supports can provide large spaces to accommodate and to support oxides, and to prevent particle agglomeration. The resulting advantages of the resistance of crossover effects and CO poisoning at graphene based transition metal oxide nanocomposite cathodes are more positive, compared to commercial Pt/C.

On this basis, we found that mono-transition metal oxide supported on graphene/graphene oxides have already exhibited good performance of the ORR and long-term durability, owing to its facial growth of abundant functionalized hydroxyl groups, stable spatial crystalline structure and high alkaline corrosion resistance. From the angle of co-catalyst of transition metal oxides, we propose that the strategy of synthesizing the bimetallic composition of transition metal oxides is necessary for further elevating the electrocatalytic activity of the ORR. The covalently bonded bimetallic oxides not only afford considerably greater activity and durability than the physical mixture of nanoparticles, the appropriate substitution of a 
transition metallic element for another transition metal can significantly mediate the size and phase of the oxides, influencing the nanocomposite catalytic performance. Therefore, it is meaningful that an effective design scheme of cationic substitution and covalent coupling with graphene supports might help to produce an advanced ORR electrocatalyst for energy conversion and storage. As for the supports of nanocomposites, it is acceptable that the meticulous design of graphene based substrates with habitable and functionalized construction, prefect structural stability and strong tolerance of acidity and alkalinity will contribute to the acceleration of adsorption and reduction of oxygen in the ORR process. Thus, developing non-defective graphene with single layer, heterogeneous functionalized 2D graphene, heteroatom-doped 3D graphene aerogel or foam as substrates is more significant. In addition, advanced structure-controlled methods and processes for the in situ synthesis of graphene based transition metal oxide nanocomposites play another important role in increasing the catalytic efficiency of the ORR. The nucleation and crystal growth of transition metal oxides are remarkably affected by precursors, calcination temperature, heating rate, atmosphere conditions and reaction times. The synthesis of morphologytunable transition metal oxides with various phases might provide valuable information on understanding not only the crystal defects on oxides but also the kinetic mechanism of oxygen reduction on the surface of nanocomposites.

It should be noted that, the challenges of graphene based transition metal oxide nanocomposites still remain to be realized in a scientific and technical way. The fundamental mechanism of the kinetic process in graphene-based nanocomposites is yet to be completely understood, especially with respect to their surface functionalities/defects and hierarchical electrode structures. On one hand, the enhancement mechanism, including the improved stability of nanoparticles on graphene's surface and the electronic interactions between graphene and nanocatalysts, is still not clear. On the other hand, the durability of graphene-based transition metal oxide nanocomposites is of crucial importance for their practical application in real fuel cells.

\section{Acknowledgements}

This work was supported financially by the Major Program of National Natural Science Foundation of China (no. 51290282), National Basic Research Program of China (no. 2011CB935704, no. 2013CB934004), and the National Natural Science Foundation of China (no. 21235004).

\section{Notes and references}

1 L. Wu, H. Feng, M. Liu, K. Zhang and J. Li, Nanoscale, 2013, 5, 10839-10843.

2 A. Kloke, F. von Stetten, R. Zengerle and S. Kerzenmacher, Adv. Mater., 2011, 23, 4976-5008.
3 V. R. Stamenkovic, B. S. Mun, M. Arenz, K. J. J. Mayrhofer, C. A. Lucas, G. Wang, P. N. Ross and N. M. Markovic, Nat. Mater., 2007, 6, 241-247.

4 X. Wang, Y. Orikasa, Y. Takesue, H. Inoue, M. Nakamura, T. Minato, N. Hoshi and Y. Uchimoto, J. Am. Chem. Soc., 2013, 135, 5938-5941.

5 V. Komanicky, A. Menzel and H. You, J. Phys. Chem. B, 2005, 109, 23550-23557.

6 N. Mahmood, C. Zhang, J. Jiang, F. Liu and Y. Hou, Chem. - Eur. J., 2013, 19, 5183-5190.

7 M. Liu, Y. Dong, Y. Wu, H. Feng and J. Li, Chemistry, 2013, 19, 14781-14786.

8 Y. Dong, Y. Wu, M. Liu and J. Li, ChemSusChem, 2013, 6, 2016-2021.

9 F. Cheng, Y. Su, J. Liang, Z. Tao and J. Chen, Chem. Mater., 2009, 22, 898-905.

10 Y. Liang, H. Wang, P. Diao, W. Chang, G. Hong, Y. Li, M. Gong, L. Xie, J. Zhou, J. Wang, T. Z. Regier, F. Wei and H. Dai, J. Am. Chem. Soc., 2012, 134, 15849-15857.

11 K.-W. Park, J.-H. Choi, B.-K. Kwon, S.-A. Lee, Y.-E. Sung, H.-Y. Ha, S.-A. Hong, H. Kim and A. Wieckowski, J. Phys. Chem. B, 2002, 106, 1869-1877.

12 J. A. Farmer and C. T. Campbell, Science, 2010, 329, 933936.

13 Z. H. Zhang, J. Liu, J. J. Gu, L. Su and L. F. Cheng, Energy Environ. Sci., 2014, 7, 2535-2558.

14 C. Xu, Y. Zhang, L. Wang, L. Xu, X. Bian, H. Ma and Y. Ding, Chem. Mater., 2009, 21, 3110-3116.

15 Y. Jiang, Y. Lu, X. Lv, D. Han, Q. Zhang, L. Niu and W. Chen, ACS Catal., 2013, 3, 1263-1271.

16 J. M. Ziegelbauer, T. S. Olson, S. Pylypenko, F. Alamgir, C. Jaye, P. Atanassov and S. Mukerjee, J. Phys. Chem. C, 2008, 112, 8839-8849.

17 G. Zhang, S. Wang and F. Yang, J. Phys. Chem. C, 2012, 116, 3623-3634.

18 W.-L. Qu, Z.-B. Wang, X.-L. Sui, D.-M. Gu and G.-P. Yin, Int. J. Hydrogen Energy, 2012, 37, 15096-15104.

19 G. Selvarani, S. Maheswari, P. Sridhar, S. Pitchumani and A. K. Shukla, J. Electrochem. Soc., 2009, 156, B1354-B1360.

20 H. Song, X. Qiu, F. Li, W. Zhu and L. Chen, Electrochem. Commun., 2007, 9, 1416-1421.

21 X.-M. Wang, J. Wang, Q.-Q. Zou and Y.-Y. Xia, Electrochim. Acta, 2011, 56, 1646-1651.

22 Z. Yang, X. Zhou, H. Nie, Z. Yao and S. Huang, ACS Appl. Mater. Interfaces, 2011, 3, 2601-2606.

23 K. S. Novoselov, A. K. Geim, S. V. Morozov, D. Jiang, Y. Zhang, S. V. Dubonos, I. V. Grigorieva and A. A. Firsov, Science, 2004, 306, 666-669.

24 S. Eigler and A. Hirsch, Angew. Chem., Int. Ed., 2014, 53, 7720-7738.

25 V. Chabot, D. Higgins, A. Yu, X. Xiao, Z. Chen and J. Zhang, Energy Environ. Sci., 2014, 7, 1564-1596.

26 M. J. Allen, V. C. Tung and R. B. Kaner, Chem. Rev., 2009, 110, 132-145.

27 K. S. Novoselov, V. I. Falko, L. Colombo, P. R. Gellert, M. G. Schwab and K. Kim, Nature, 2012, 490, 192-200. 
28 H. Chen and X. Guo, Small, 2013, 9, 1144-1159.

29 Y. Huang, J. Liang and Y. Chen, Small, 2012, 8, 18051834.

30 W. Zhang, F. Liu, Q. Li, Q. Shou, J. Cheng, L. Zhang, B. J. Nelson and X. Zhang, Phys. Chem. Chem. Phys., 2012, 14, 16331-16337.

31 Z. Zhu, L. Garcia-Gancedo, A. J. Flewitt, H. Xie, F. Moussy and W. I. Milne, Sensors, 2012, 12, 5996-6022.

32 D. Chen, L. Tang and J. Li, Chem. Soc. Rev., 2010, 39, 3157-3180.

33 G. Xie, K. Zhang, B. Guo, Q. Liu, L. Fang and J. R. Gong, Adv. Mater., 2013, 25, 3820-3839.

34 H. Li, L. Zou, L. Pan and Z. Sun, Environ. Sci. Technol., 2010, 44, 8692-8697.

35 Y. Sun, D. Shao, C. Chen, S. Yang and X. Wang, Environ. Sci. Technol., 2013, 47, 9904-9910.

36 G. Zhao, J. Li, X. Ren, C. Chen and X. Wang, Environ. Sci. Technol., 2011, 45, 10454-10462.

37 L. Dai, Acc. Chem. Res., 2012, 46, 31-42.

38 D. Eder, Chem. Rev., 2010, 110, 1348-1385.

39 D.-W. Wang and D. Su, Environ. Sci. Technol., 2014, 7, 576591.

40 Y. Liu, Y.-Y. Wu, G.-J. Lv, T. Pu, X.-Q. He and L.-L. Cui, Electrochim. Acta, 2013, 112, 269-278.

41 L. Lin, M. Li, L. Jiang, Y. Li, D. Liu, X. He and L. Cui, J. Power Sources, 2014, 268, 269-278.

42 Y. Ma, H. Wang, J. Key, V. Linkov, S. Ji, X. Mao, Q. Wang and R. Wang, Int. J. Hydrogen Energy, 2014, 39, 1477714782.

43 Z.-S. Wu, S. Yang, Y. Sun, K. Parvez, X. Feng and K. Müllen, J. Am. Chem. Soc., 2012, 134, 9082-9085.

44 X. Gao, J. Wang, Z. Ma and J. Ye, Electrochim. Acta, 2014, 130, 543-550.

45 L. Cui, G. Lv, Z. Dou and X. He, Electrochim. Acta, 2013, 106, 272-278.

46 V. K. Singh, M. K. Patra, M. Manoth, G. S. Gowd, S. R. Vadera and N. Kumar, New Carbon Mater., 2009, 24, 147-152.

47 Z. Ma, X. Huang, S. Dou, J. Wu and S. Wang, J. Phys. Chem. C, 2014, 118, 17231-17239.

48 P.-A. Pascone, D. Berk and J.-L. Meunier, Catal. Today, 2013, 211, 162-167.

49 D. Wang, Q. Zhang, K. Zhou, W. Yang, Y. Hu and X. Gong, J. Hazard. Mater., 2014, 278, 391-400.

50 S. Yang, G. Cui, S. Pang, Q. Cao, U. Kolb, X. Feng, J. Maier and K. Müllen, ChemSusChem, 2010, 3, 236-239.

51 M. Wang, J. Huang, M. Wang, D. Zhang, W. Zhang, W. Li and J. Chen, Electrochem. Commun., 2013, 34, 299-303.

52 Y. Wang, X. Ma, L. Lu, Y. He, X. Qi and Y. Deng, Int. J. Hydrogen Energy, 2013, 38, 13611-13616.

53 J. Xu, J. Wu, L. Luo, X. Chen, H. Qin, V. Dravid, S. Mi and C. Jia, J. Power Sources, 2015, 274, 816-822.

54 J. Wang, J. Zhou, Y. Hu and T. Regier, Energy Environ. Sci., 2013, 6, 926-934.

55 Y. Liang, Y. Li, H. Wang, J. Zhou, J. Wang, T. Regier and H. Dai, Nat. Mater., 2011, 10, 780-786.
56 Y. Liang, H. Wang, J. Zhou, Y. Li, J. Wang, T. Regier and H. Dai, J. Am. Chem. Soc., 2012, 134, 3517-3523.

57 Y. Yang, H. Fei, G. Ruan, C. Xiang and J. M. Tour, ACS Nano, 2014, 8, 9518-9523.

58 M. Fu, Q. Jiao and Y. Zhao, Mater. Charact., 2013, 86, 303315.

59 S. Guo, S. Zhang, L. Wu and S. Sun, Angew. Chem., Int. Ed., 2012, 51, 11770-11773.

60 J.-S. Lee, G. S. Park, H. I. Lee, S. T. Kim, R. Cao, M. Liu and J. Cho, Nano Lett., 2011, 11, 5362-5366.

61 L. Mao, D. Zhang, T. Sotomura, K. Nakatsu, N. Koshiba and T. Ohsaka, Electrochim. Acta, 2003, 48, 1015-1021.

62 I. Roche, E. Chaînet, M. Chatenet and J. Vondrák, J. Phys. Chem. C, 2006, 111, 1434-1443.

63 Q. Tang, L. Jiang, J. Liu, S. Wang and G. Sun, ACS Catal., 2013, 4, 457-463.

64 X. Zhu, P. Zhang, S. Xu, X. Yan and Q. Xue, ACS Appl. Mater. Interfaces, 2014, 6, 11665-11674.

65 S. Bag, K. Roy, C. S. Gopinath and C. R. Raj, ACS Appl. Mater. Interfaces, 2014, 6, 2692-2699.

66 Y. Qian, S. Lu and F. Gao, Mater. Lett., 2011, 65, 56-58.

67 A. Ramírez, P. Hillebrand, D. Stellmach, M. M. May, P. Bogdanoff and S. Fiechter, J. Phys. Chem. C, 2014, 118, 14073-14081.

68 Q. Wen, S. Wang, J. Yan, L. Cong, Z. Pan, Y. Ren and Z. Fan, J. Power Sources, 2012, 216, 187-191.

69 J. Wu, D. Zhang, Y. Wang and Y. Wan, Electrochim. Acta, 2012, 75, 305-310.

70 L. J. Fu, J. Gao, T. Zhang, Q. Cao, L. C. Yang, Y. P. Wu and R. Holze, J. Power Sources, 2007, 171, 904-907.

71 Z. Ai, H. Xiao, T. Mei, J. Liu, L. Zhang, K. Deng and J. Qiu, J. Phys. Chem. C, 2008, 112, 11929-11935.

72 D. J. Davis, T. N. Lambert, J. A. Vigil, M. A. Rodriguez, M. T. Brumbach, E. N. Coker and S. J. Limmer, J. Phys. Chem. C, 2014, 118, 17342-17350.

73 R. Zhou, Y. Zheng, D. Hulicova-Jurcakova and S. Z. Qiao, J. Mater. Chem. A, 2013, 1, 13179-13185.

74 X.-Y. Yan, X.-L. Tong, Y.-F. Zhang, X.-D. Han, Y.-Y. Wang, G.-Q. Jin, Y. Qin and X.-Y. Guo, Chem. Commun., 2012, 48, 1892-1894.

75 A. L. Hsu, R. J. Koch, M. T. Ong, W. Fang, M. Hofmann, K. K. Kim, T. Seyller, M. S. Dresselhaus, E. J. Reed, J. Kong and T. Palacios, ACS Nano, 2014, 8, 7704-7713.

76 A. Ishihara, M. Tamura, Y. Ohgi, M. Matsumoto, K. Matsuzawa, S. Mitsushima, H. Imai and K.-i. Ota, J. Phys. Chem. C, 2013, 117, 18837-18844.

77 K. Tiido, N. Alexeyeva, M. Couillard, C. Bock, B. R. MacDougall and K. Tammeveski, Electrochim. Acta, 2013, 107, 509-517.

78 Y. Zhan, C. Xu, M. Lu, Z. Liu and J. Y. Lee, J. Mater. Chem. A, 2014, 2, 16217-16223.

79 M. Chigane and M. Ishikawa, J. Chem. Soc., Faraday Trans., 1998, 94, 3665-3670.

80 P. Efstathiou, X. Xu, H. Menard and J. T. S. Irvine, Dalton Trans., 2013, 42, 7880-7887. 
81 R. Ferrando, J. Jellinek and R. L. Johnston, Chem. Rev., 2008, 108, 845-910.

82 C. Hsu, C. Huang, Y. Hao and F. Liu, Nanoscale Res. Lett., 2013, 8, 1-7.

83 J. Xiao, L. Wan, X. Wang, Q. Kuang, S. Dong, F. Xiao and S. Wang, J. Mater. Chem. A, 2014, 2, 3794-3800.

84 Q. Wu, L. Jiang, L. Qi, L. Yuan, E. Wang and G. Sun, Electrochim. Acta, 2014, 123, 167-175.

85 L. Qu, Y. Liu, J.-B. Baek and L. Dai, ACS Nano, 2010, 4, 1321-1326.

86 R. Zhang and W. Chen, J. Mater. Chem. A, 2013, 1, 1145711464.

87 T. Ando, M. Ishii, M. Kamo and Y. Sato, J. Chem. Soc., Faraday Trans., 1993, 89, 1783-1789.

88 K. Gajjar, L. D. Heppenstall, W. Pang, K. M. Ashton, J. Trevisan, I. I. Patel, V. Llabjani, H. F. Stringfellow, P. L. Martin-Hirsch, T. Dawson and F. L. Martin, Anal. Methods, 2013, 5, 89-102.

89 S. Yang, X. Song, P. Zhang and L. Gao, ACS Appl. Mater. Interfaces, 2013, 5, 3317-3322.

90 S. Das, A. S. Wajid, J. L. Shelburne, Y.-C. Liao and M. J. Green, ACS Appl. Mater. Interfaces, 2011, 3, 18441851.

91 S. Wang, D. Yu, L. Dai, D. W. Chang and J.-B. Baek, ACS Nano, 2011, 5, 6202-6209.

92 M. Zhang, Z. Yan, Q. Sun, J. Xie and J. Jing, New J. Chem., 2012, 36, 2533-2540.

93 Y. Liu, S. Shrestha and W. E. Mustain, ACS Catal., 2012, 2, 456-463.

94 M. Sawangphruk, P. Srimuk, P. Chiochan, A. Krittayavathananon, S. Luanwuthi and J. Limtrakul, Carbon, 2013, 60, 109-116.

95 K. Erickson, R. Erni, Z. Lee, N. Alem, W. Gannett and A. Zettl, Adv. Mater., 2010, 22, 4467-4472.

96 F. Q. Song, Z. Y. Li, Z. W. Wang, L. He, M. Han and G. H. Wang, Ultramicroscopy, 2010, 110, 1460-1464.

97 J. C. Koepke, J. D. Wood, D. Estrada, Z.-Y. Ong, K. T. He, E. Pop and J. W. Lyding, ACS Nano, 2012, 7, 75-86.

98 I. Jung, M. Vaupel, M. Pelton, R. Piner, D. A. Dikin, S. Stankovich, J. An and R. S. Ruoff, J. Phys. Chem. C, 2008, 112, 8499-8506.

99 K. A. Mkhoyan, A. W. Contryman, J. Silcox, D. A. Stewart, G. Eda, C. Mattevi, S. Miller and M. Chhowalla, Nano Lett., 2009, 9, 1058-1063.

100 G. Dong and J. W. M. Frenken, ACS Nano, 2013, 7, 70287033.

101 E. Y. Polyakova, K. T. Rim, D. Eom, K. Douglass, R. L. Opila, T. F. Heinz, A. V. Teplyakov and G. W. Flynn, ACS Nano, 2011, 5, 6102-6108.

102 Z. Sun, Z. Yan, J. Yao, E. Beitler, Y. Zhu and J. M. Tour, Nature, 2010, 468, 549-552.

103 R. J. Nicholls, A. T. Murdock, J. Tsang, J. Britton, T. J. Pennycook, A. Koós, P. D. Nellist, N. Grobert and J. R. Yates, ACS Nano, 2013, 7, 7145-7150.

104 O. Roslyak, G. Gumbs and D. Huang, Physica E, 2012, 44, 1874-1884.
105 H. Chen, Y. Li, F. Zhang, G. Zhang and X. Fan, J. Mater. Chem., 2011, 21, 17658-17661.

106 G. Xi, J. Ye, Q. Ma, N. Su, H. Bai and C. Wang, J. Am. Chem. Soc., 2012, 134, 6508-6511.

107 J. Shen, X. Li, N. Li and M. Ye, Electrochim. Acta, 2014, 141, 126-133.

108 Q. Tang, Z. Shan, L. Wang and X. Qin, Electrochim. Acta, 2012, 79, 148-153.

109 M. Sun, Y. Dong, G. Zhang, J. Qu and J. Li, J. Mater. Chem. A, 2014, 2, 13635-13640.

110 M. Jahan, Q. Bao and K. P. Loh, J. Am. Chem. Soc., 2012, 134, 6707-6713.

111 J. Chlistunoff, J. Phys. Chem. C, 2011, 115, 6496-6507.

112 C.-C. Chou, C.-H. Liu and B.-H. Chen, Energy, 2014, 70, 231-238.

113 C. Du, Y. Sun, T. Shen, G. Yin and J. Zhang, in Rotating Electrode Methods and Oxygen Reduction Electrocatalysts, ed. W. X. Y. Zhang, Elsevier, Amsterdam, 2014, DOI: 10.1016/B978-0-444-63278-4.00007-0, pp. 231-277.

114 H. Zhu, S. Zhang, Y.-X. Huang, L. Wu and S. Sun, Nano Lett., 2013, 13, 2947-2951.

115 S. Zhang, H. Zhang, Q. Liu and S. Chen, J. Mater. Chem. A, 2013, 1, 3302-3308.

116 X. Fu, J. Jin, Y. Liu, Q. Liu, K. Niu, J. Zhang and X. Cao, Electrochem. Commun., 2013, 28, 5-8.

117 I. Kruusenberg, J. Mondal, L. Matisen, V. Sammelselg and K. Tammeveski, Electrochem. Commun., 2013, 33, 18-22.

118 D. D. Zhu, L. J. Li, J. J. Cai, M. Jiang, J. B. Qi and X. B. Zhao, Carbon, 2014, 79, 544-553.

119 A. Kong, Y. Kong, X. Zhu, Z. Han and Y. Shan, Carbon, 2014, 78, 49-59.

120 O. Tripachev, V. Bogdanovskaya, M. Tarasevich and V. Andoralov, J. Electroanal. Chem., 2012, 683, 21-24.

121 M. Ciureanu and R. Roberge, J. Phys. Chem. B, 2001, 105, 3531-3539.

122 K.-M. Nam, D.-H. Shin, N. Jung, M. G. Joo, S. Jeon, S.-M. Park and B.-Y. Chang, Anal. Chem., 2013, 85, 22462252.

123 H. Huang and X. Wang, J. Mater. Chem. A, 2014, 2, 62666291.

124 X. Yu, L. Kuai and B. Geng, Nanoscale, 2012, 4, 57385743.

125 X. Zhao, M. Yin, L. Ma, L. Liang, C. Liu, J. Liao, T. Lu and W. Xing, Energy Environ. Sci., 2011, 4, 2736-2753.

126 J. O. Bockris and T. Otagawa, J. Electrochem. Soc., 1984, 131, 290-302.

127 M. Xia, Y. Liu, Z. Wei, S. Chen, K. Xiong, L. Li, W. Ding, J. Hu, L.-J. Wan, R. Li and S. F. Alvia, J. Mater. Chem. A, 2013, 1, 14443-14448.

128 J. Xu, D. Aili, Q. Li, C. Pan, E. Christensen, J. O. Jensen, W. Zhang, G. Liu, X. Wang and N. J. Bjerrum, J. Mater. Chem. A, 2013, 1, 9737-9745.

129 Q. Wu, L. Jiang, Q. Tang, J. Liu, S. Wang and G. Sun, Electrochim. Acta, 2013, 91, 314-322.

130 S. Chen, Z. Wei, X. Qi, L. Dong, Y.-G. Guo, L. Wan, Z. Shao and L. Li, J. Am. Chem. Soc., 2012, 134, 13252-13255. 
131 W. Zhou, L. Ge, Z.-G. Chen, F. Liang, H.-Y. Xu, J. Motuzas, A. Julbe and Z. Zhu, Chem. Mater., 2011, 23, 4193-4198.

132 Q. Li, P. Xu, B. Zhang, H. Tsai, S. Zheng, G. Wu and H.-L. Wang, J. Phys. Chem. C, 2013, 117, 13872-13878.

133 S. Lee, J. Y. Cheon, W. J. Lee, S. O. Kim, S. H. Joo and S. Park, Carbon, 2014, 80, 127-134.

134 X. Xia, W. Lei, Q. Hao, W. Wang, Y. Sun and X. Wang, Electrochim. Acta, 2013, 113, 117-126.

135 J. Wu, D. Zhang, Y. Wang, Y. Wan and B. Hou, J. Power Sources, 2012, 198, 122-126.

136 J.-M. You, H. S. Han, H. K. Lee, S. Cho and S. Jeon, Int. J. Hydrogen Energy, 2014, 39, 4803-4811.
137 Y. Hou, Y. Cheng, T. Hobson and J. Liu, Nano Lett., 2010, 10, 2727-2733.

138 I. Roche and K. Scott, J. Electroanal. Chem., 2010, 638, 280-286.

139 Z. Lei, F. Shi and L. Lu, ACS Appl. Mater. Interfaces, 2012, 4, 1058-1064.

140 A. K. Sinha, M. Pradhan and T. Pal, J. Phys. Chem. C, 2013, 117, 23976-23986.

141 A. Elzatahry, A. Abdullah, T. El-Din, A. Al-Enizi, A. Maarouf, A. Galal, H. Hassan, E. El-Ads, S. Al-Theyab and A. Al-Ghamdi, Int. J. Electrochem. Sci., 2012, 7, 31153119. 